\title{
ORGANIZACIÓN DELICTIVA BASES PARA SU ELABORACIÓN DOGMÁTICA EN EL DERECHO PENAL CHILENO
}

\author{
FELONIOUS ORGANIZATION \\ BASIS FOR ITS DOCTRINAL CONSTRUCTION IN CHILEAN CRIMINAL LAW
}

\section{JuAN PABlo MaÑalich R.*}

RESUMEN: El artículo propone una diferenciación de tres niveles de análisis para reconstruir dogmáticamente el fenómeno de la "criminalidad organizada", según la función específica que asume, en cada caso, el factor organizacional: la de contexto, objeto o sujeto de responsabilidad jurídico-penal. En el nivel del contexto, se examina el problema de la determinación de las modalidades de autoría que pueden venir en consideración en el marco de organizaciones jerarquizadas. En el nivel del objeto, se defiende la tesis del injusto autónomo de la asociación ilícita. Y en el nivel del sujeto, en referencia directa al régimen de responsabilidad establecido por la Ley 20.393, se afirma la posibilidad de recurrir al concepto de culpabilidad por el carácter para fundamentar la responsabilidad de la organización configurada como persona jurídica.

Palabras clave: organizaciones, autoría, asociación ilícita, responsabilidad de personas jurídicas, culpabilidad por el carácter.

ABSTRACT: The article proposes a differentiation of three analytical levels for the doctrinal reconstruction of the phenomenon of "organized crime", according to the specific function displayed by the organizational factor in each case: the function of context, object or subject of criminal responsibility. The problem of determining the pertinent forms of principal intervention in the realm of hierarchal organizations is reviewed at the context-level. At the object-level, the article argues in favor of the autonomous wrongdoing of unlawful association. And at the subject-level, by direct reference to the grounds of responsibility established by Act 20.393, the possibility of construing a concept of culpability for character is considered, in order to give basis to criminal corporate liability.

Key words: organizations, principal intervention, unlawful association, criminal corporate liability, culpability for character.

${ }^{*}$ Licenciado en Ciencias Jurídicas y Sociales, Universidad de Chile (2004), Doctor en Derecho, Universidad de Bonn (2008). Dirección de correo electrónico: jpmanalich@derecho.uchile.cl. El autor agradece los comentarios y la valiosa ayuda editorial prestada por Javier Contesse S., investigador del Centro de Estudios de la Justicia, y Julio Tapia O., ayudante del Departamento de Ciencias Penales, ambos de la Facultad de Derecho de la Universidad de Chile. 


\section{EL DESAFÍO ONTOLÓGICO}

Lo que existe, existe con independencia de nuestras actitudes y creencias: que creamos que X es el caso no implica que X sea el caso. Pero la identificación de lo que existe no es independiente del aparato conceptual con arreglo al cual clasificamos lo existente; esta es la tarea de la ontología: producir el mejor inventario -entre varios posibles- del universo. Nuestras posibilidades de dar cuenta, adecuadamente, de lo que existe, son dependientes de la adecuación del aparato conceptual del cual nos valemos para ello. Y la hipótesis global que se intentará someter a verificación es que el conjunto de los problemas más agudos que trae consigo la discusión acerca de la así llamada "criminalidad organizada", al menos en el ámbito de referencia pertinente para el discurso de la dogmática jurídicopenal, es de tipo ontológico: no contamos con el aparato conceptual adecuado para dar cuenta, satisfactoriamente, de los diferentes niveles en que el tema "criminalidad organizada" impone preguntas que vuelven necesarias respuestas diferenciadas.

Este trabajo cuenta como un ejercicio orientado a la clarificación de los términos de esa discusión, en pos de la identificación de los diferentes niveles en que el tópico de la organización delictiva exige una tematización dogmática articulada. Y aquí no debería pasar de contrabando la sustitución terminológica que acaba de ser introducida. La etiqueta "criminalidad organizada" muestra una vocación primariamente criminológica, que puede ser de utilidad para el discurso de la así llamada "política criminal", como agenda de preocupación primariamente fenoménica. Pero mientras prevalezca una orientación fenoménica hacia el problema de la interrelación entre las categorías "delito" y “organización”, nuestras posibilidades de elaboración dogmática se verán gravemente comprometidas. Por eso cabe hablar, en lo que sigue, del problema de la "organización delictiva” como objeto de referencia idóneo del discurso de la dogmática jurídico-penal.

\section{2. ¿LA ORGANIZACIÓN DELICTIVA COMO SISTEMA DE INJUSTO?}

La ventaja de esta terminología se encuentra en que ella pone el énfasis, tal como se expresa en la posición del sustantivo de la frase, en el factor organizacional como plataforma de agencia delictiva. Y a este respecto se vuelve manifiesto el déficit de las distintas articulaciones del aparato conceptual disponible; y esto, incluso tratándose de aquellas propuestas más sofisticadas. Un buen ejemplo lo provee la célebre distinción, introducida por Lampe, entre "sistemas de injusto simple" y "sistemas de injusto constituido" ${ }^{1}$. Siendo todo sistema de injusto (con relevancia jurídico-penal) un conjunto de "relaciones entre individuos organizadas hacia fines injustos" 2 , un sistema de injusto será simple en la medida en que el sistema se halle organizado "hacia un fin común a través de la voluntad de los individuos" que integran el sistema ${ }^{3}$, mientras que un sistema de injusto será -o estará- constituido en tanto su organización adquiera una "configuración

\footnotetext{
${ }^{1}$ LAMPE (2003) pp. 97 ss., 103 ss.

2 LAMPE (2003) p. 103.

${ }^{3}$ LAMPE (2003) p. 104.
} 
institucional duradera mediante una constitución o unos estatutos" ${ }^{4}$. Como instancia paradigmática de sistema de injusto simple, Lampe menciona la coautoría; como instancias de sistemas de injusto constituido, en cambio, la organización criminal, la empresa económica con tendencia criminal, así como los Estados y las estructuras estatales criminalmente pervertidos 5

La propuesta de Lampe muestra ventajas considerables frente a otros intentos de conceptualización. Pues se trata de una concepción que alcanza a tematizar estructuras de injusto cuyo "parecido de familia" se encuentra asociado a una determinada manifestación del factor organizacional, pero que no se reduce a la adopción de un punto de vista puramente fenoménico para dar cuenta, diferenciadamente, de ellas. Así por ejemplo, Lampe logra producir una fundamentación bastante precisa de la diferente estructura de injusto que caracteriza a la coautoría como sistema de injusto simple, por una parte, y a la agrupación criminal (o "asociación ilícita") como sistema de injusto constituido, por otra.

En lo que aquí interesa, cabe restringir el análisis a la contraposición entre la agrupación criminal (o asociación ilícita) y la empresa con tendencia criminal. En tanto instancias de sistema de injusto constituido, lo que ellas tendrían en común es que sus respectivos "elementos de pertenencia" serían "independientes de la persona de sus miembros", lo cual conllevaría un considerable incremento del grado de complejidad de la organización, que se expresaría, verbigracia, en una alta jerarquización y selectividad de la comunicación al interior de la misma ${ }^{6}$. Lo que las diferenciaría, en cambio, sería el hecho de que la agrupación criminal constituye un sistema de injusto en razón de una agenda (o "finalidad") criminal que define -o en todo caso codefine- su estructura interna, mientras que el injusto de una empresa económica con tendencia criminal no sería "esencial sino únicamente accidental” para su propia organización 7 .

Así, en una organización criminal aparecerían los siguientes factores determinantes para su respectiva forma de injusto constituido: el potencial humano y técnico disponible para la planificación y ejecución delictiva; la firme organización externa que hace posible un dominio de la voluntad común; una finalidad criminal sistémicamente constitutiva; y una disposición interna de adhesión que se desarrollaría progresivamente entre los miembros ${ }^{8}$. Para el injusto constituido de una empresa con tendencia criminal, por su parte, los factores determinantes serían: el peligro potencial de la organización empresarial, mecánica o lógicamente dispuesta para la respectiva prestación; el déficit de la respectiva estructura organizacional; una filosofía empresarial criminógena; y una erosión de la noción de responsabilidad por la acción individual ${ }^{9}$.

\footnotetext{
${ }^{4}$ LAMPE (2003) p. 111.

5 LAMPE (2003) pp. 104 ss., 111 ss., quien tangencialmente sugiere que las bandas también podrían ser entendidas como sistemas de injusto simple, en tanto lo que en ellas falta no es una organización, sino el carácter institucional de esta (p. 115).

${ }^{6}$ LAMPE (2003) p. 112.

7 LAMPE (2003) pp. 127 ss.

${ }^{8}$ LAMPE (2003) p. 128.

9 LAMPE (2003) p. 131.
} 
Hasta aquí, la propuesta constructiva de Lampe parece ser prometedora, en virtud de su rendimiento diferenciador. Pero es precisamente un déficit de diferenciación lo que, contra las apariencias, en definitiva trae consigo su propuesta. Esto se advierte al atender a su tematización del complemento necesario de la noción de sistema de injusto, a saber: la noción de la responsabilidad por el respectivo injusto del sistema ${ }^{10}$. En general, lo que determina la modalidad de responsabilidad correspondiente es la propia estructura del respectivo sistema, según se trate de uno simple o de uno constituido. Así, el hecho de que en la coautoría se dé solo un sistema de injusto simple explicaría, según Lampe, que no tenga sentido plantear la pregunta de la eventual responsabilidad del propio sistema (colectivo) por el injusto sistémico. Pues en la coautoría el sistema -en tal medida, "simple" - se agota en la realización del hecho, imputable individualmente a cada uno de los coautores como personas responsables ${ }^{11}$.

Tratándose de instancias de sistema de injusto constituido, la solución podría ser distinta, dado que aquí el respectivo sistema sí se caracteriza por una estructura institucionalizada que le confiere existencia más allá de la realización de uno o más hechos delictivos particulares. Sin embargo, y en lo que aquí interesa, solo la empresa con tendencia criminal sería, según Lampe, capaz de soportar una atribución de responsabilidad sistémica, no así la organización criminal. Esto, porque la organización empresarial existe como organización jurídicamente reconocida, esto es, como persona, de modo tal que el derecho puede hacerla responsable ${ }^{12}$. En cambio, puesto que la organización criminal, en tanto tal, no puede pretender reconocimiento jurídico, resulta descartada sin más la posibilidad de que la propia organización sea hecha responsable ${ }^{13}$. Esta sería la razón, según Lampe, por la cual solo los miembros de la organización responden, en virtud de su pertenencia a la organización, de la existencia de esta.

La razón para haber dedicado especial atención al modelo elaborado por Lampe se encuentra en que el mismo representa un intento sofisticado de producir una concepción estructural de una dogmática de la organización delictiva. Sin embargo, el modelo del injusto del sistema no alcanza a explicar cabalmente dónde radica la diferencia específica entre las distintas formas de injusto sistémico, al menos por referencia a las dos instancias de mayor significación en el ámbito de lo que Lampe denomina "sistemas de injusto constituido": la organización criminal y la empresa con tendencia criminal. Pues siguiendo a Lampe, la diferencia parecería reducirse al hecho de que solo la segunda obtiene reconocimiento jurídico de personalidad como base de responsabilidad. Pero esto supone entender que la diferencia sería reconocible en un mismo nivel de referencia. Y como se sostendrá a continuación, ello no es el caso. El sentido específico en que la variable organizacional se hace relevante para la estructura de imputación de la coautoría, para el injusto de la organización criminal (o "asociación ilícita") y para la responsabilidad penal de una empresa dotada de personalidad jurídica, no es el mismo.

\footnotetext{
${ }^{10}$ LAMPE (2003) pp. 141 ss.

11 LAMPE (2003) p. 146.

12 LAMPE (2003) pp. 155 ss.

13 LAMPE (2003) pp. $152 \mathrm{~s}$.
} 


\section{LA ORGANIZACIÓN: CONTEXTO, OBJETO, SUJETO}

El factum de la organización puede tener relevancia jurídico-penal en tres niveles distintos. En primer término, una organización puede tener relevancia como contexto de imputación; en segundo lugar, como objeto de imputación; y en tercer lugar, como sujeto de imputación. Cada uno de estos tres niveles se corresponde con un ámbito de elaboración dogmática diferenciada.

Cuando se trata de la pregunta de la organización como contexto de responsabilidad, la cuestión se plantea en relación con las categorías de la parte general que ofrecen los criterios de responsabilidad aplicables en el ámbito de la intervención de varias personas en un mismo hecho delictivo. En este nivel, el factor organizacional no tiene impacto alguno en la identificación del objeto de imputación; su incidencia se agota, más bien, en la posibilidad de que una determinada estructura organizacional-criminal, empresarial, militar, etc.- haga operativos determinados criterios de imputación, específicamente pertinentes ${ }^{14}$. En este nivel, por ejemplo, cobra sentido la discusión acerca de la demarcación entre la autoría mediata y la coautoría -o bien entre alguna de estas y alguna forma de intervención accesoria- en el ámbito de los así llamados "aparatos organizados de poder".

Frente a ello, la especificidad jurídico-penal de la asociación ilícita recién se deja advertir cuando el factor organizacional pasa a ser definitorio de un objeto de imputación determinado. El injusto de la asociación ilícita constituye, de este modo, un específico injusto objetivo, que se corresponde con la realización de un tipo delictivo determinado, a saber: precisamente el de la asociación ilícita como delito de pertenencia. Y esta y no otra es la razón por la cual, en principio al menos, solo a los miembros de la organización resulta imputable el injusto de la asociación ilícita. Pues es la pertenencia a esta lo que cuenta, entonces, como objeto de imputación jurídico-penal.

Y finalmente: la imposibilidad, advertida por Lampe, de que una misma organización sea definida como criminal per se, por un lado, y a la vez pueda ser portadora de responsabilidad por hechos de significación criminal, por otro, se muestra como una trivialidad una vez que se reconoce que en esta última pregunta se trata de la organización como sujeto mismo de responsabilidad. Es en este nivel donde se sitúa la discusión acerca de la viabilidad de un régimen de genuina responsabilidad jurídico-penal de personas jurídicas, discusión que en el marco del derecho chileno, a partir de la entrada en vigencia de la Ley 20.393, ha perdido su tono especulativo.

\section{LA ORGANIZACIÓN: CONTEXTO DE IMPUTACIÓN}

\section{1. ¿COAUTORÍA VERSUS AUTORÍA MEDIATA?}

La principal dificultad que cabe advertir en este nivel se encuentra en la hipótesis de que la variable organizacional determinaría la pertinencia de una determinada estruc-

${ }^{14}$ Para la distinción analítica entre el objeto y los criterios de imputación, véase MAÑALICH (2009a) pp. 23 ss.; MAŃALICH (2010a) pp. 165 ss. 
tura de imputación por antonomasia frente a la pregunta de la configuración y distribución de la responsabilidad, al interior de la organización, por uno o más hechos delictivos determinados. Notablemente, se trata de una premisa compartida por un conjunto bastante heterogéneo de propuestas de articulación dogmática. Por una parte, ella aparece en la identificación, sugerida por Lampe, de la coautoría como forma paradigmática de un sistema de injusto simple. Por otra, la premisa también aparece en la célebre construcción de Roxin, relativa al así llamado "dominio de la organización" como criterio específico de autoría mediata ${ }^{15}$.

Puede ser particularmente útil detenerse en esta última construcción. Y no solo por su celebridad. Lo esencial está, antes bien, en la prioridad que esta concepción otorga a la consideración - puramente fenoménica- de que, al interior de una organización verticalmente jerarquizada y desacoplada del ordenamiento jurídico, por definición se encontraría excluida la posibilidad de reconocer una coautoría en relación con uno o más hechos delictivos específicos ${ }^{16}$, de modo tal que la única forma de autoría que podría venir en consideración respecto del "hombre del escritorio" sería la autoría mediata. Aquí es de interés, por una parte, que este intento de construcción de una autoría mediata resulte ciertamente imposible de compatibilizar con el "principio de responsabilidad”, sobre el cual descansa la estructura de imputación de la autoría mediata, cuando esta es normativamente articulada: la imputación del hecho al autor de mediato exige un déficit de responsabilidad jurídico-penal de la "persona de adelante", a través de cuyo actuar ("de propia mano") se realiza el hecho ${ }^{17}$. No existiendo un déficit de responsabilidad jurídico-penal en la persona de adelante -el cual podría consistir tanto en la falta de satisfacción de algún presupuesto de su capacidad de seguimiento de la norma como en la falta de un injusto objetivo predicable de su actuar-, ella cuenta como autora directa del hecho, sin que pueda venir en consideración, entonces, la imputabilidad del mismo hecho a otra persona a título de autoría.

Pero es igualmente determinante en contra de la construcción de Roxin, por otra parte, la circunstancia de que sea enteramente viable la construcción de una "coautoría vertical", sin que ello conlleve una distorsión de sus presupuestos específicos ${ }^{18}$. Lo importante es advertir, en el marco del derecho chileno, que la regulación legal hace

\footnotetext{
15 RoXIN (2006) pp. 11 ss. Puede ser útil observar, de paso, que esta concepción se diferencia, de modo no irrelevante, de la concepción original de Roxin en cuanto a la estructura de la autoría mediata en el marco de aparatos organizados de poder. Pues en la primera formulación se trataba, exclusivamente, de un caso específico de autoría mediata por "dominio de la voluntad", de modo tal que el instrumento se correspondía con la persona del ejecutor (fungible), que ocupa una posición de inferioridad en la organización respectiva. Así RoXIN (2000) pp. 269 ss. De acuerdo con su más reciente concepción, en cambio, ya no se trataría de un caso específico de autoría mediata por "dominio de la voluntad", sino de una forma de autoría mediata sui generis, que descansaría en un "dominio de la organización". La consecuencia fundamental de ello, que Roxin no duda en extraer explícitamente, radica en que como "instrumento" del autor mediato habría que considerar no al ejecutor, sino a la propia organización: "[e]l verdadero instrumento es más bien el aparato como tal" (Roxin [2006] p. 14).

${ }^{16}$ ROXIN (2006) p. 13.

$17 \mathrm{Al}$ respecto MAÑALICH (2010b) pp. 396 ss.

${ }^{18}$ Así LAMPe (2007) pp. 508 ss.
} 
posible el recurso a la estructura de la coautoría en tales constelaciones. Para ello es suficiente una interpretación coordinada del art. 15 del Código Penal, de conformidad con la cual se reconozca el carácter subordinado de la variante de coautoría identificada por referencia al concierto previo (art. 15 No 3) respecto de la variante de coautoría que exige que el interviniente tome parte en la ejecución del hecho (art. 15 No 1). Esto quiere decir, ciertamente, que el art. $15 \mathrm{No} 1$ comprende (exclusivamente) una forma de coautoría identificada bajo un criterio objetivo, consistente en la exigencia de una contribución individual que se materialice en la realización de una acción ejecutiva ${ }^{19}$. Esto presupone, ahora bien, la proposición igualmente fundamental de que "acción ejecutiva" y "acción típica" no son términos sinónimos, ya que de lo contrario sería imposible diferenciar la coautoría ("ejecutiva”) de la autoría directa, entendiendo esta última como la forma (paradigmática) de autoría que corresponde a aquel a quien resulta inmediata y exclusivamente imputable la realización - "de propia mano"- del tipo delictivo, la cual, como forma de autoría individualmente autosuficiente, no queda comprendida por el art. 15 del Código Penal ${ }^{20}$. Pues de quien, mediante su propio actuar, realiza íntegramente el tipo delictivo, no puede decirse que tome parte en la ejecución del hecho ${ }^{21}$. Por

${ }^{19}$ A favor de esta tesis cabe remitirse al análisis, ofrecido por GIMBERNAT (2007) pp. 3 ss., 73 ss., del art. 14 No 1 del Código Penal español de 1944, bajo el cual se consideraban autores "los que toman parte directa en la ejecución del hecho". Un aspecto fundamental de la tesis de Gimbernat se encuentra en la observación de que la aplicabilidad de esa regla presuponía ya la intervención de varias (= dos o más) personas que se distribuyen -sin necesidad de un acuerdo previo, así como tampoco de un "acuerdo de momento" (= acuerdo concluyente)- la ejecución de la respectiva realización típica. Es importante tener en cuenta que Gimbernat rechazaba la tendencia de la jurisprudencia del Tribunal Supremo español de aquel entonces, en el sentido de interpretar esta disposición a modo de una configuración subjetivista de los presupuestos de la coautoría de conformidad con la "teoría del acuerdo previo" (pp. 41 ss.), en circunstancias, sin embargo, que ninguno de los numerales de ese art. 14 contemplaba una regla similar a la del art. 15 No 3 del Código Penal chileno.

20 Esto es solo sugerido por YÁNEZ (1975) p. 56, quien observa que el art. 15 del Código Penal solo sería aplicable a "situaciones en que interviene en el hecho delictivo más de una persona". Lo mismo vale, en todo caso, para la autoría mediata. Pues en tanto forma de autoría puramente individual, ella no queda siquiera comprendida por la referencia genérica del art. 14. Si bien la autoría mediata presupone el involucramiento de otro como agente deficitario a través de cuyo actuar tiene lugar la realización del tipo, en ningún caso se trata de un interviniente responsable en el mismo hecho que resulta imputable al autor mediato. El art. 15 No 2 tendría que ser interpretado como abarcando exclusivamente la intervención constitutiva de inducción. Pues el autor mediato no fuerza o induce a otro a ejecutar el hecho, sino que realiza el hecho a través del actuar del otro. La variante de inducción consistente en forzar a otro a la ejecución del hecho debe ser entendida, por lo mismo, como referida a la situación de aquel que coercitivamente influye a favor de la ejecución del hecho por parte de otro, sin que este vea comprometida su responsabilidad en virtud de esa coacción, la cual en tal medida no debe alcanzar el umbral de la exculpación por fuerza (psíquica) irresistible o miedo insuperable (art. 10 No $9 \mathrm{CP}$ ), lo cual no alcanza a ser advertido por YÁNEZ (1975) p. 62. La función del art. 15 No 2, por ende, solo consiste en equiparar la penalidad asociada a la inducción a la que corresponde al autor, sin que ello revierta en modo alguno la necesidad de que se satisfagan sus presupuestos generales, exigidos por el principio de accesoriedad de la participación.

${ }^{21}$ Gimbernat (2007) pp. 84 ss., quien concluye que el "autor en sentido estricto" no queda(ba) comprendido por el art. 14 del Código Penal español de 1944 (pp. 190 s.). Para una interpretación del art. 15 No 1 del Código Penal chileno en el sentido de una "coautoría inmediata e indirecta", véase NovOA (2005) pp. 182 ss. 
ende, la exigencia de una contribución ejecutiva ha de entenderse como la exigencia de que el interviniente en cuestión efectúe una contribución que por sí misma tendría que exhibir relevancia ejecutiva, con lo cual resulta excluida, por ejemplo, una coautoría en el sentido del art. $15 \mathrm{No} 1$ en caso de que el interviniente se limite a efectuar una contribución puramente preparatoria ${ }^{22}$.

$\mathrm{Y}$ es enteramente posible interpretar el art. $15 \mathrm{No} 3$, por su parte, en el sentido de una configuración primariamente subjetivista de los presupuestos de una forma dependiente de coautoría, bajo la cual la exigencia de concierto previo sustituye la exigencia de una contribución ejecutiva, siempre que la contribución no-ejecutiva del sujeto concertado con otros para la ejecución del hecho sea de relevancia bajo el esquema común de interpretación del hecho conjuntamente organizado ${ }^{23}$. Que se trate aquí de una forma de coautoría dependiente significa que la intervención de uno o más coautores "concertados" en el sentido del art. 15 No 3 necesariamente presupone la intervención de al menos dos coautores "ejecutivos" en el sentido del art. 15 No 1 . Pues si solo se tiene a la vista la intervención de personas que "facilitan los medios con que se lleva a efecto el hecho o lo presencian sin tomar parte inmediata en él" ${ }^{24}$, entonces no resulta imaginable cómo pudiera llegar a ejecutarse el hecho. Por eso, la existencia de coautores en el sentido del art. 15 No 3 presupone la existencia de coautores en el sentido del art. 15 № 1.

\subsection{UN EJEMPLO: LA AUTORÍA EN LA ORGANIZACIÓN MILITAR}

Que esta lectura de la regulación legal es plausible, para fundamentar así la coautoría ("vertical") de quienes, ocupando posiciones de (relativa) superioridad e inferioridad en una organización jerarquizada, no necesariamente toman parte en la ejecución del hecho delictivo, apenas se deja poner en duda si se pone la vista en las disposiciones pertinentes del Código de Justicia Militar. Pues con arreglo a su art. 214, la responsabilidad exclusiva del superior que ha impartido la orden cuya ejecución era obligatoria para el subordinado -lo cual se corresponde, entonces, con una autoría mediata (del superior) por actuación justificada del instrumento- decae habiendo "concierto previo", en cuyo caso "serán responsables todos los concertados" 25.

Esto vuelve necesario, por de pronto, clarificar un malentendido que parece gobernar la interpretación doctrinal del art. 214 del Código de Justicia Militar. Pues se halla sumamente difundida la sugerencia de que este reconocimiento legal explícito de la responsabilidad del superior que ha impartido la orden contaría como refutación insalvable de la tesis de la obediencia debida como causa de justificación para el subordinado que cumple la orden; de lo contrario, se dice, habría que asumir "que la misma acción pueda estar al mismo tiempo prohibida para uno y permitida (justificada) para otro, lo

\footnotetext{
22 Así YÁneZ (1975) pp. 54 ss.

23 Véase KINDHÄUSER (2003) pp. 65 ss.

${ }^{24} \mathrm{La}$ variante de coautoría consistente en presenciar el hecho "sin tomar parte inmediatamente en él" debería ser entendida en el sentido de que la presencia de ese interviniente ha de tener relevancia decisiva desde el punto de vista del esquema común de interpretación del hecho que vincula a los coautores, esto es, desde el punto de vista del concierto para la ejecución común del hecho. Así YÁnEZ (1975) p. 61.

${ }^{25}$ En detalle al respecto MAÑALICH (2008) pp. 68 ss.
} 
cual es inadmisible"26. Lo que explica la confusión subyacente a este planteamiento es el desconocimiento del carácter relativo-a-la-persona-del-autor del juicio de justificación de un comportamiento bajo una determinada regla permisiva ${ }^{27}$, que es justamente lo que hace posible, por lo demás, la fundamentación de una autoría mediata en los casos de actuación justificada del instrumento (o "persona de adelante") ${ }^{28}$.

La relatividad personal del juicio de justificación es reconocible, precisamente, en la situación del subordinado que se halla jurídicamente obligado a dar cumplimiento a la orden impartida por su superior ${ }^{29}$. De este modo, la imputación del comportamiento del subordinado -cuando este es por sí mismo constitutivo de la realización típica correspondiente- como acción propia al superior se ajusta a la exigencia impuesta por el principio de responsabilidad, que exige que el hecho no sea (ordinariamente) imputable a la persona de adelante, en tanto instrumento del autor mediato, como infracción de deber culpable ${ }^{30}$. Pues de conformidad con el principio de responsabilidad, la autoría mediata de la "persona de atrás" depende, en primer término, de la existencia de un déficit de responsabilidad jurídico-penal de la "persona de adelante", por el cual aquella ha de ser competente ${ }^{31}$; así como, en segundo término, de que en la "persona de atrás" se satisfagan todos los demás presupuestos del carácter delictivo del hecho.

En virtud del cumplimiento del respectivo deber de obediencia, el actuar subordinado puede quedar cubierto por una causa de justificación en el sentido del art. 10 No 10 del Código Penal, en circunstancias que el superior resulta específicamente competente por la justificación del comportamiento del subordinado. Se trata, entonces, de un caso nominativo de autoría mediata por actuación justificada del instrumento. Para el

${ }^{26}$ CURY (2005) p. 462; en igual sentido ETCHEBERry (1998) p. 353, quien cree ver en ello "una imposibilidad lógica”. No deja de impresionar que Etcheberry hable de una “aporía” a propósito de una eventual afirmación del carácter justificado del cumplimiento de la orden tendiente a la comisión de un delito y no advierta aporía alguna en la "solución" de negar la existencia de un deber jurídico de cumplir la orden, que tendría que explicar cómo puede fundamentarse entonces la punibilidad del subordinado, a título de delito de desobediencia, en caso que el mismo omita cumplirla.

27 Que se trate de un juicio relativo a la persona del autor quiere decir que el juicio de justificación modifica el estatus normativo del hecho principal en tanto atribuido al respectivo autor, de modo tal que quienes intervienen accesoriamente en el hecho no son partícipes de injusto alguno, de conformidad con el principio de la accesoriedad media o limitada.

28 Esto no solo es propio de los casos de actuación justificada del instrumento, sino también de aquellos en que su propia autolesión resulta imputable, como heterolesión en autoría mediata, a la "persona de atrás". Latamente al respecto MAÑALich (2009a) pp. 167 ss.; MAÑALiCH (2010b) pp. 405 ss.

${ }^{29}$ En contra de lo sugerido por NOVOA (2005) p. 399, que el art. 214 del Código de Justicia Militar hable de que "se haya cometido delito por la ejecución de una orden del servicio" no obsta a esta consideración. Pues correspondiendo entonces una imputación de la ejecución de la orden como acción propia al superior, la misma sigue constituyendo delito.

${ }^{30}$ La exigencia de un defecto de imputación ordinaria en la "persona de adelante" se explica por el hecho de que la autoría mediata de la "persona de atrás" también puede fundamentarse en caso que la "persona de adelante" actúe bajo un déficit de imputación ordinaria que no excluya, sin embargo, una imputación extraordinaria a su respecto. Este es el caso, por ejemplo, cuando en la "persona de adelante" se da un error de tipo vencible, que deje a salvo la posibilidad de un reproche a título de imprudencia. Al respecto MAÑALICH (2010b) pp. 400 ss. Para la distinción entre ambas formas de imputación (ordinaria y extraordinaria) con relevancia jurídico-penal, véase MAÑALICH (2009a) pp. 67 ss.; MAÑALICH (2010a) pp. 175 ss.

31 Al respecto MAÑALiCH (2010b) pp. 396 ss. 
ámbito en que rige el principio de responsabilidad exclusiva del superior, empero, el inc. $2^{\circ}$ del mismo art. 214 del Código de Justicia Militar sujeta la exención de responsabilidad del subordinado al cumplimiento de la "formalidad" enunciada en el art. 335, que consiste en dar cuenta al superior de que la orden tiende notoriamente a la perpetración de un delito, en circunstancias de que, en todo caso, ha de tratarse de una orden que el superior haya podido impartir en uso de sus atribuciones legítimas. Habiendo observado el subordinado ese requisito procedimental, y habiendo sin embargo el superior insistido en la orden, el subordinado puede esgrimir la obligatoriedad de su comportamiento para así resultar plenamente exento de responsabilidad. No habiendo observado ese requisito procedimental, empero, el subordinado recibe en todo caso una atenuación de responsabilidad, que se expresa en una reducción (obligatoria) en un grado de la pena asignada al delito cometido en ejecución de la orden ${ }^{32}$.

La responsabilidad primaria del superior se funda en su competencia exclusiva por la obligatoriedad jurídica del comportamiento del subordinado, que desde el punto de vista de una persona leal a derecho conlleva la "necesidad práctica" del mismo: "deber" equivale, entonces, a "tener que" 33 . Y de modo plenamente congruente con ello cabe dar cuenta, en lo que aquí importa, de la excepción que la segunda parte del inc. $1^{\circ}$ del art. 214 del Código de Justicia Militar establece para el caso de concierto previo, independientemente de que entre los concertados pueda haber superiores y subordinados. Pues lo que el concierto previo produce -tal como lo muestra la regla del art.15 No 3 del Código Penal- es una modificación de la estructura de imputación, que pasa a ser la de la coautoría, que por oposición a la autoría mediata se distingue por el hecho de que cada uno de los intervinientes asume el actuar de cada uno de los demás como actuar propio, de modo tal que, en el sentido de la doctrina del "hecho conjunto" (Gesamttat), a cada uno resulta imputable el comportamiento de cada uno de los demás como acción propia. Se trata aquí, por ende, de una competencia común en virtud de organización conjunta del hecho, que descansa en un esquema de representación recíproca ${ }^{34}$.

\footnotetext{
32 Esto admite fundamentarse como el reconocimiento de un debilitamiento de la eficacia eximente del carácter jurídicamente obligatorio del cumplimiento de la orden por la omisión del ejercicio de esa facultad de representación, sin que ello erosione el fundamento de la imputabilidad del hecho en que se traduce el cumplimiento de la orden como acción propia al superior que la ha impartido. Esta interpretación se ve apoyada, por lo demás, en el hecho de que el propio inc. $2^{\circ}$ del art. 214 del Código de Justicia Militar establezca la misma rebaja de pena aplicable al subordinado que, estando obligado a cumplir la orden, "se hubiera excedido en su ejecución". Pues aquí es claro que el subordinado es responsable de una dimensión del hecho delictivo que no resulta imputable al superior que impartiera la orden en cuestión, es decir, de una dimensión del hecho en relación con la cual está excluida la eventual responsabilidad del superior como autor, sin que el subordinado pueda aparecer, por ende, como cómplice; él cuenta, más bien, como autor (directo) del hecho definido por una circunstancia que excede el margen de lo imputable al superior (en tanto autor mediato), lo cual hace posible evitar la constatación de un "autor detrás del autor" en relación con $e l$ mismo hecho. Por ello, es llamativo que la generalidad de la doctrina nacional asuma, sin ofrecer ulterior fundamentación, que el subordinado ejecutor de la orden respondería, en el primer caso, a título de cómplice. Así Novoa (2005) p. 399; ETCHeberRy (1998) p. 352; CURY (2005) p. 467.

33 Para esta construcción de la autoría mediata en los casos de actuación justificada del instrumento, MAÑALICH (2010b) pp. $404 \mathrm{~s}$.

${ }^{34}$ Fundamental KINDHÄUSER (2003) pp. 65 ss.
} 
Lo anterior solo tiene la pretensión de haber dado cuenta de la manera en que el derecho vigente reconoce la posibilidad de hacer operativas estructuras de imputación diferenciadas en atención a determinadas constelaciones en que la variable organizacional se hace específicamente operativa, como contexto de una atribución de responsabilidad a personas vinculadas organizacionalmente. Baste concluir el ejercicio señalando que sigue estando pendiente, en el marco del derecho chileno, una revisión acabada de las posibilidades constructivas de ajustar las categorías dogmáticas relativas a la intervención delictiva múltiple a los requerimientos específicos de la imputación subjetiva a título de imprudencia ${ }^{35}$.

\section{LA ORGANIZACIÓN: OBJETO DE IMPUTACIÓN}

\section{1. ¿PROBLEMA DE LA PARTE GENERAL?}

En el derecho chileno, el problema de la organización como objeto de responsabilidad jurídico-penal encuentra su asidero preciso en la tipificación de los delitos de asociación ilícita. En atención al panorama actual de la vocación estatal de persecución penal de determinadas agrupaciones identificadas por una agenda (supuestamente) delictiva, el principal desafío sigue estando en una determinación sustantiva de los contornos del ámbito típico de la asociación ilícita, que posibilite la elaboración de parámetros de aplicación racional de las respectivas normas de sanción. Pues es sin duda en este nivel donde aparecen los mayores excesos punitivistas en la persecución penal de la "criminalidad organizada".

Aquí es imprescindible tomar nota de algunas propuestas de reconstrucción dogmática de los "delitos de organización" que se ventilan en la discusión comparada. Pues ante estos desarrollos se hace patente la necesidad de identificar adecuadamente la especificidad del respectivo nivel de relevancia del factor organizacional. La consideración del intercambio reciente entre dos connotados penalistas españoles -Manuel Cancio Meliá y Jesús Silva Sánchez- es de máximo interés a este respecto. Notablemente, Cancio y Silva dicen compartir una premisa, a saber: que aquí se trataría, "materialmente" al menos, de un problema de la dogmática de la parte general ${ }^{36}$. Una de las razones por las cuales resulta tan interesante concentrarse en su intercambio, ahora bien, se halla en que esa premisa de hecho no es compartida. Pues solo Silva, y no Cancio, enfrenta el problema intentando reconducirlo a la esfera de la parte general.

La razón que ofrece Cancio a favor de reconducir la reconstrucción del injusto de la asociación ilícita a la dogmática de la parte general responde a una variable que en efecto pertenece, sin embargo, al núcleo de la parte especial: la identificación de la específica lesividad de una determinada forma delictiva. Cancio destaca, en primer término, el "elemento colectivo", cuyo peso específico en la configuración del injusto de la pertenencia a una organización llevaría, en segundo término, a que aquel se encuentre

35 Indiciariamente al respecto VAN WEEZEL (2009) pp. 442 ss., con nota 54.

${ }^{36}$ CANCIO (2008) pp. 29 s.; SILVA (2008) p. 94. 
alejado "de toda lesión concreta" 37 . A partir de esto, Cancio emprende una revisión exhaustiva de las distintas posibilidades teóricas disponibles para fundamentar un injusto específico de la asociación ilícita.

Descartando rápidamente la antigua apelación a la noción de un ejercicio abusivo del derecho de asociación, Cancio se concentra en tres propuestas alternativas: primero, la que recurre a la noción de un adelantamiento de la punibilidad, en términos de la teoría de la anticipación, por referencia a la protección de los bienes jurídicos directamente menoscabos por los delitos cuya perpetración constituye el objeto de la organización, que sería la favorecida por Silva; segundo, la que recurre a la noción del menoscabo de un bien jurídico colectivo, altamente "espiritualizado"; y tercero, la propuesta de Jakobs, que recurre a la noción de un "injusto de amenaza", entendido como el quebrantamiento de una "norma de flanqueo", cuya función sería dotar de un mínimo de seguridad cognitiva a las correspondientes "normas principales", cuyo quebrantamiento es ordinariamente delictivo ${ }^{38}$. Tras criticar, en lo fundamental, las dos aproximaciones tradicionales - anticipación de la protección vía adelantamiento de la punibilidad, postulación de un bien jurídico colectivo hiperdesmaterializado-, Cancio elabora una propuesta que procura, rescatando con matices la concepción de Jakobs y reorientándola hacia el núcleo de la variable organizacional, identificar el desafío al monopolio estatal de la violencia como el contenido de injusto específico de la asociación ilícita, en el sentido de una "arrogación de organización política"39.

Aquí no interesa evaluar los méritos de la reconstrucción del injusto de la asociación ilícita propuesta por Cancio, que en lo fundamental se orienta a recuperar su "significado político". Lo relevante es constatar que, de hecho, se trata de un ejercicio de elaboración dogmática que inequívocamente se mantiene dentro del juego de lenguaje que caracteriza a la dogmática de la parte especial. Y es precisamente esto lo que pone en cuestión la propuesta de Silva Sánchez, que en tal medida admite ser descrita como un intento de disolución del injusto específico de los delitos de organización. Esto, porque una reelaboración del planteamiento fundamental que subyace a la teoría de la anticipación tendría que hacer posible perfilar el significado preciso de la variable organizacional en este ámbito: se trataría, según Silva, de "un sistema de acumulación institucionalizada de aportaciones individuales favorecedoras de la ejecución de los delitos-fin de la asociación delictiva" ${ }^{40}$. Y aquí hay que advertir que hablar, en estos términos, de "los delitos-fin de la asociación delictiva", es redundante. Pues el esfuerzo de Silva está dirigido a mostrar la conveniencia de renunciar a la idea de que la sola asociación constituya "un delito que existe por el solo hecho de organizarse”, como dispone, sin embargo, el art. 292 del Código Penal chileno.

\footnotetext{
37 CANCIO (2008) p. 29.

38 CANCIO (2008) pp. 30 ss., 35 ss. Para la tercera propuesta véase JAKOBS (1997) pp. 293 ss., 313 ss., donde se desarrolla la tesis del "injusto meramente parcial" asociado al quebrantamiento de tales normas de flanqueo.

39 CANCIO (2008) pp. 51 ss. Para una crítica de la tesis, sobre todo asociada a la obra de García-Pablos, que postula la autotutela del poder estatal como objeto de protección de la prohibición de la asociación ilícita, véase GUZMÁN DALBORA (2007) pp. 99 ss.

40 SILVA (2008) p. 100.
} 


\section{2. ¿LA ORGANIZACIÓN COMO MARCO DE INTERVENCIÓN DELICTIVA?}

La maniobra argumentativa crucial que despliega Silva Sánchez se encuentra en su presentación de los dos grandes modelos de lo que él denomina la "atribución de responsabilidad penal a los miembros de las organizaciones criminales", a saber: el modelo de la transferencia y el modelo de responsabilidad por el hecho propio ${ }^{41}$. No está de más notar que son precisamente estos los términos en que tiende a plantearse la contraposición de los modelos de hetero- y autorresponsabilidad en la discusión acerca de la responsabilidad jurídico-penal de las personas jurídicas ${ }^{42}$. Esto tiene alguna relevancia, en tanto muestra que Silva Sánchez no está dispuesto a reconocer que al problema del injusto de la asociación ilícita corresponda un nivel de referencia autónomo. Pues Silva rechaza, al menos implícitamente, la idea de que la sola integración de -o pertenencia a- una determinada organización pueda tener relevancia delictiva per se. Si se recurre a la idea de un injusto de pertenencia, que él equipara a la de un injusto de adhesión, entonces -sostiene Silva- lo que en efecto se valida es un régimen de "transferencia de responsabilidad a (cada uno de) sus miembros por el 'ser' de la organización" 43 .

Esta última puntualización es decisiva para comprender adecuadamente el planteamiento de Silva. Pues este afirma, inmediatamente a continuación, que "la adhesión de cada miembro [...] puede constituir, ciertamente, un criterio de transferencia de responsabilidad", la cual, sin embargo, exhibiría una "naturaleza distinta [...] de la que caracteriza a las formas convencionales de intervención en el delito" ${ }^{44}$. Lo que Silva parece no aceptar como posibilidad, por ende, es que la pertenencia a la organización no constituya un criterio de atribución de responsabilidad por algo distinto, sino más bien el objeto de una atribución de responsabilidad, esto es, el objeto de una imputación estrictamente individual.

Lo anterior ciertamente no invalida la exploración de una construcción distinta, como la que emprende el propio Silva al fundamentar una variante específica del modelo de responsabilidad por el hecho propio, que él designa como un modelo de "responsabilidad por intervención 'a través de organización"” 45 . En lo fundamental, Silva se aparta de la idea según la cual el factor organizacional pudiera traducirse en una mera variable de agravación o "cualificación" de la intervención en el o los respectivos hechos delictivos en definitiva cometidos por los miembros de la organización. Su tesis postula, en cambio, una "doble función de garantía delictiva" que desempeñaría la organización: la garantía de la pervivencia del riesgo creado por cada miembro, así como la garantía de la conexión de dicho riesgo con aquel generado por los intervinientes en un determinado hecho delictivo particular. Así, la intervención a través de la organización, operando esta al modo de una plataforma de amplificación de la capacidad de contribución delictiva

\footnotetext{
41 SILVA (2008) pp. 101 ss.

42 Véase infra, 6.2.

43 SiLVA (2008) pp. 102 s.

44 SILVA (2008) p. 103.

45 Silva (2008) pp. 108 ss.
} 
de cada miembro, asumiría la forma de una "intervención accesoria en el injusto abstractamente referida a la organización" 46 .

Lo esencial de la construcción defendida por Silva se halla en su esfuerzo por mantener una comprensión de la pertenencia a una organización criminal como un criterio de intervención personal en hechos delictivos distintos de esa sola organización; esta no sería, entonces, un hecho delictivo por sí mismo, sino un criterio de intervención, eventualmente anticipada -esto es, sometida a un adelantamiento de la punibilidad en comparación con el inicio de la tentativa del respectivo "delito-fin"-, adaptado a la existencia de "organizaciones criminales" ${ }^{4}$. La consecuencia fundamental consistiría en que, aun bajo semejante adelantamiento de la punibilidad, el comportamiento del interviniente "por organización" solo resultaría merecedor de sanción penal en caso de constituir una forma de participación en el delito respectivo si este llegase a alcanzar el inicio de la tentativa ${ }^{48}$.

\subsection{LA AUTONOMÍA DE INJUSTO DE LA ASOCIACIÓN ILÍCITA}

El problema está en si tal modelo de fundamentación es capaz de dar cuenta, siquiera mínimamente, de la respectiva regulación legal. Y al menos teniendo a la vista los datos básicos del modelo regulativo que hace suyo la legislación chilena, la respuesta negativa es rotunda. La consecuencia recién apuntada, en el sentido de que la "intervención a través de organización" solo resultaría punible en caso de llegar a tener relevancia (anticipada) como forma de participación (lato sensu) en un determinado hecho delictivo particular que alcanzara el inicio de la tentativa, es precisamente lo que el derecho chileno exige no para el injusto de la asociación ilícita, sino para el injusto ("dependiente”) de la conspiración, como forma de acción preparatoria excepcionalmente punible. Pues esta requiere que dos o más personas se concierten para la ejecución de un determinado hecho delictivo (art. $8^{\circ}$ inc. $2^{\circ} \mathrm{CP}$ ), el cual, de alcanzar el inicio de la tentativa, en principio les sería imputable, ceteris paribus y por defecto ${ }^{49}$, a título de coautoría en virtud del concierto previo (art. 15 No $3 \mathrm{CP}$ ).

La consideración anterior no vale, sin embargo, tratándose de una asociación ilícita. Pues aquí no se trata de una mera anticipación de la punibilidad de una forma de intervención por referencia a la ejecución futura de un determinado hecho delictivo. La manera más fácil de advertirlo consiste en preguntarse por la respectiva relación de concurso que se produce en caso de que llegue a ejecutarse, al menos en grado de tentativa, algún hecho que pueda contar como el respectivo "delito fin". En el caso de la conspiración, precisamente en virtud de su carácter de injusto dependiente, lo correcto es reconocer su preterición en virtud de un concurso aparente fundado en su carácter de

\footnotetext{
46 SILVA (2008) p. 110.

47 SILVA (2008) p. 111.

48 SiLVA (2008) p. 116.

49 Por defecto, porque en la medida que su contribución a la realización del hecho resulte ejecutiva, en el sentido del art. 15 No 1 del Código Penal, entonces será esta la modalidad de coautoría bajo la cual habrá que encuadrar su intervención. Véase supra, 4.1.
} 
hecho anterior copenado. Pero es manifiesto que esta solución, que sería la más consistente con la propuesta de Silva Sánchez, no es la prevista en relación con la de asociación ilícita, al menos en el marco del derecho chileno, según dispone el art. 294 bis del Código Penal.

Así, el injusto de la asociación ilícita no se presenta en modo alguno como un injusto dependiente de algún determinado hecho delictivo futuro a ser ejecutado por sus miembros. Ciertamente, lo que confiere carácter delictivo a la sola organización consiste en una agenda delictiva, en el sentido de que el objeto mismo (o "giro") de la asociación ha de ser la perpetración de hechos delictivos de determinadas características, lo cual hace posible, por lo demás, clasificar las distintas variantes de asociación ilícita: el delito base, tipificado en los arts. 290 y siguientes del Código Penal, exige que el objeto de la asociación consista en la perpetración de hechos constitutivos de crímenes o simples delitos; las formas especiales, como la asociación ilícita terrorista, la asociación ilícita para el tráfico de estupefacientes, o la asociación ilícita para el lavado de dinero, que el objeto consista en la perpetración de hechos adscritos a un específico ámbito delictivo. Pero nada de ello obsta a la consideración de que el injusto específico de la asociación ilícita se encuentra configurado de modo plenamente autónomo respecto del injusto específico de los eventuales delitos múltiples cuya perpetración constituye el objeto de la asociación ${ }^{50}$.

Ello se ve ciertamente reforzado por la existencia de una regla expresa que declara que la sanción penal del delito de asociación ilícita es independiente de la sanción penal de "los crímenes o simples delitos cometidos" en el marco de la organización (art. 294 bis CP) ${ }^{51}$. Esto es determinante, en tanto muestra que la representación legislativa de un injusto independiente vuelve necesario reconocer como auténtico (no aparente) el eventual concurso, el cual tendrá que calificarse como ideal o real según se satisfagan o no los presupuestos de una "unidad de hecho" 52 . Y esto, hasta el punto de que, tratándose de una asociación ilícita para el narcotráfico, el eventual concurso queda sometido, por

50 Acertadamente GUZMÁN DALBORA (2007) pp. 161 ss.

51 En tanto la regulación de la forma básica de asociación ilícita de los arts. 292 y ss. del CP constituye lex generalis respecto de las variantes previstas por la legislación especial, es posible concluir que el principio de la punibilidad autónoma fijado en el art. 294 bis resulta aplicable por defecto en tales ámbitos específicos. Ello es de particular relevancia para aquellos ámbitos regulativos que no prevén una declaración expresa que determine el régimen de penalidad del posible concurso entre el delito de asociación ilícita y los eventuales delitos particulares cometidos en su marco; este es el caso, por ejemplo, tratándose de la asociación ilícita para el lavado de activos (art. 28 Ley 19.913).

52 Ello tendría que depender de si la intervención en el hecho delictivo específico por parte del miembro de la organización constituye una manifestación de su pertenencia a la asociación, en cuyo caso cabría en principio reconocer una unidad de acción, que fundamentaría un concurso ideal. Así razona la doctrina alemana dominante, como sugiere KINDHÄUSER (2010) \$129, n.m. 50. En contra del reconocimiento de un concurso ideal (en vez de un concurso real) cabría esgrimir, ahora bien, que la manifestación incidental de pertenencia (o adhesión) a la organización asociada a la intervención en la perpetración de algún hecho delictivo específico no alcanza a fundamentar una unidad de acción entre esa intervención delictiva específica y la totalidad del comportamiento de integración (o adhesión) permanente, constitutivo de asociación ilícita. A favor de la tesis del concurso real se pronuncia, por ejemplo, GUZMÁn Dalbora (2007) p. 163, nota 150 . 
declaración legal expresa, al régimen de la acumulación material de penas del art. 74 del Código Penal (art. 16 inc. final Ley 20.000) (33 $^{2}$

Bajo la representación legislativa es inequívoco, entonces, que el injusto de la asociación ilícita es enteramente independiente del injusto de los eventuales hechos delictivos específicos cuya perpetración constituye el objeto de la asociación. Esto es decisivo para reconocer que ese injusto independiente solo puede ser plausiblemente identificado con la forma de menoscabo de bienes jurídicos representada por el peligro abstracto, entendido como la afectación de aquellas condiciones generales de seguridad de las cuales depende la posibilidad de una disposición despreocupada sobre uno o más bienes jurídicos por parte de su(s) titular(es) ${ }^{54}$. Solo determinando exactamente en qué puede consistir este "peligro abstracto de organización” resultará posible elaborar criterios de subsunción de los respectivos comportamientos de pertenencia individual a la organización bajo las correspondientes modalidades típicas, orientados a la racionalización de la aplicación de las respectivas normas de sanción. Ello exige advertir, por de pronto, que el peligro abstracto de organización es relativo al sujeto, y no al objeto; pero además, que es subjetiva y no objetivamente relativo al sujeto ${ }^{55}$ : no se trata del peligro abstracto identificado con una situación (objetiva) de incapacidad de controlar una determinada fuente de peligro, sino con una disposición (subjetiva) a la perpetración futura de múltiples e indefinidos hechos delictivos.

Irónicamente, la única manera de racionalizar mínimamente la tipificación de la integración individual de una organización criminal como delito autónomo consiste en perfilar las condiciones objetivas de los cuales depende que la pertenencia a la organización cuente como expresión contextualmente suficiente de esa disposición (subjetiva) colectivamente compartida ${ }^{56}$. De lege lata, esto se traduce, por de pronto, en exigencias

\footnotetext{
53 Esto último tiene la importancia adicional de poner de manifiesto que el legislador, al excluir la eventual aplicabilidad del régimen de acumulación jurídica del art. 351 del Código Procesal Penal, parece asumir que la lesividad específica de la asociación ilícita para el narcotráfico es independiente de la lesividad de los delitos de tráfico de estupefacientes, puesto que el presupuesto de aplicabilidad de ese régimen es que el concurso real (la "reiteración") se dé entre delitos de la misma especie, esto es, que constituyan un menoscabo para un bien jurídico (art. 351 inc. final CPP).

54 Fundamental KindHÄUSER (1989) pp. 277 ss.; KindHÄUSER (2008) pp. 52 ss., 55 ss. Bajo esta definición del concepto de peligro abstracto, carece de toda pertinencia la tradicional apelación a la noción de "peligrosidad estadística".

55 La formulación de estas distinciones se encuentra en KINDHÄUSER (1989) pp. 311 ss.

${ }^{56}$ Esto hace posible dar cuenta de que legislador chileno reconozca un injusto plenamente independiente en el delito de asociación ilícita, sin que ocurra lo mismo tratándose del delito de amenaza simple, cuya penalidad queda sometida, en los términos del art. 296 No 3, a una regla de subsidiariedad expresa, de modo tal que si el cumplimiento de la amenaza (simple), consistente en la efectiva irrogación del mal anunciado, constituye un hecho delictivo que conlleve mayor penalidad, el delito de amenaza simple resulta desplazado -en el sentido de un concurso aparente- como hecho anterior copenado. Lo cual sugiere que la sola disposición subjetiva - manifestada en la seriedad y verosimilitud de la amenaza- a la perpetración futura de un determinado hecho delictivo no alcanza, bajo la representación legislativa, a constituir un injusto plenamente independiente del injusto representado por la efectiva irrogación del mal anunciado a modo de amenaza. Y esto muestra, por lo demás, que la tesis del “injusto de amenaza" carece de rendimiento suficiente para caracterizar la específica lesividad de la asociación ilícita, al menos de cara al derecho chileno vigente.
} 
relativas a la propia estructura de la organización, que ha de mostrar suficiente "densidad" 57 , tanto en cuanto a su proyección temporal como en cuanto a su complejidad interna: número de miembros ${ }^{58}$, distribución de funciones, etc. Pero también se traduce en exigencias relativas al propio comportamiento de integración individual de la organización así estructurada, precisamente porque es este comportamiento individual de integración lo que resulta personalmente imputable. Desde ya, cabría exigir algo más que una mera adhesión pasiva ${ }^{59}$, por más problemática que sea la diferenciación legal de las diversas modalidades de integración, e incluso de sola colaboración sin pertenencia (art. 294, $2^{\text {a }}$ parte $\left.\mathrm{CP}\right)^{60}$. Esto significa, en todo caso, que el "hecho" delictivo constitutivo de asociación ilícita es un comportamiento individual de vinculación práctica -de mayor o menor intensidad- a una estructura colectiva organizada ${ }^{61}$.

Lo anterior tiene dos consecuencias fundamentales. Por una parte, y en tanto no se trata aquí de la "intervención" en un hecho conjunto, a cada integrante se imputa su pertenencia (o adhesión) a la organización -el hecho constitutivo de asociación, en el sentido del comportamiento asociativo ("asociarse"), y no de su resultado ("asociación" ${ }^{62}$ - a título de autoría directa ${ }^{63}$. Y ello no implica hacer responsable al integrante de un "hecho ajeno", consistente en el conjunto de circunstancias que le confieren relevancia delictiva autónoma a la organización misma. Pues estas circunstancias son las que fundamentan, desde la perspectiva legislativa, la prohibición individualizada de

\footnotetext{
57 Sobre ello CANCIO (2008) p. 83. Para una decidida relativización de la importancia del factor organizacional en este sentido, véase, sin embargo, GUZMÁn DALBORA (2007) pp. 131 ss., quien no reconoce una conexión esencial entre los conceptos de asociación y organización. En contra de ello cabría esgrimir, en todo caso, que ya la definición de asociación ilícita del art. 292 del CP establece, expresamente, que la asociación ha de "organizarse".

58 Con total independencia de cómo se perfilen las demás condiciones estructurales de la organización, su número de integrantes en ningún caso puede ser inferior a tres. Esto se sigue, como conclusión a fortiori, una vez que se acepta que ya para la existencia de una banda o cuadrilla criminal son necesarias tres personas. Al respecto Toepel (2003) pp. 72 s. Para la exigencia mínima de tres miembros como presupuesto típico del delito de formación de una organización criminal bajo el $\$ 129$ del StGB, véase por todos KINDHÄUSER $(2010) \$ 129$, n.m. 6. Esto es desconocido por CARNEVALLI y FUENTES (2008), pp. 5 s.

59 Véase CANCIO (2010) pp. 157 ss.

${ }^{60}$ Críticamente, en referencia al $\$ 129$ del StGB, LAMPE (2003) pp. $153 \mathrm{~s}$.

${ }^{61}$ Ello justifica entender el quebrantamiento individual de la prohibición de la asociación ilícita como un delito de manifestación. Así acertadamente GUZMÁn Dalbora (2007) pp. 128 ss.

${ }^{62}$ En igual sentido GUZMÁN DALBORA (2007) pp. 129 s., quien correctamente advierte que la estructura de un delito de resultado es compatible sin más con la de un delito de peligro abstracto (p. 128). Esto, porque lo distintivo de un delito de resultado es que su consumación dependa de la producción de la modificación de un estado, con total independencia de si esa modificación es constitutiva de una lesión, un peligro concreto o un peligro abstracto para el objeto de protección de la respectiva norma de comportamiento. Así KindHÄUSER (1989) p. 145. Desconocen la estructura de delito de resultado (de peligro abstracto) de la asociación ilícita, empero, CARNEVALLI y FUENTES (2008) p. 5.

63 Así ya BINDING (1905) t. II, p. 909. Ello no se ve modificado por la eventual caracterización de la asociación ilícita como delito de convergencia unilateral, pues lo que único que ello significa es que cada autoría individual tiene como presupuesto la autoría individual de alguna otra persona, lo cual es enteramente dependiente del factor organizacional constitutivo de la forma de injusto. Coincidentemente a este respecto GUZMÁn DALBORA (2007) pp. 146 ss.
} 
constituir ("fundar") o integrar una organización de tales características ${ }^{64}$. Por otra parte, esta concepción también hace posible diferenciar el injusto específico de la asociación ilícita, por un lado, del injusto específico susceptible de ser predicado de aquellas variantes típicas calificadas asociadas a la perpetración de determinados hechos delictivos en el seno de estructuras colectivas más simples, por otro: la banda o cuadrilla, entendida como condición-marco que eventualmente - esto es, bajo la correspondiente determinación legislativa- intensifica, en términos de un peligro abstracto de organización, el quebrantamiento individualmente imputable de la norma respectiva ${ }^{65}$.

Nada de esto, ciertamente, alcanza aún la pregunta por la eventual conformidad constitucional de la regulación jurídico-penal de los delitos de asociación ilícita. A este respecto, el problema parece consistir, más bien, en la plena adecuación constitucional de la regulación. Para esto, basta con advertir que, al menos en términos sociopolíticos, el ámbito en que la aplicación de las normas de sanción de la asociación ilícita está adquiriendo connotaciones más abusivas es el correspondiente a la tipificación del delito de asociación ilícita terrorista (art. 2o No 5 Ley 18.314). Pero en esto el legislador parece seguir fielmente el diseño constitucional, que no solo establece un mandato de tipificación específica de delitos terroristas (art. 9o CPR), sino que impone, además, un régimen diferenciado para la recuperación de la ciudadanía cuya pérdida se sigue, también por mandato constitucional, de la condena respectiva (art. 17 No 3 , inc. final CPR) ${ }^{66}$. Y parece ser más que una casualidad que el otro ámbito delictivo constitucionalmente sometido a este mismo régimen excepcional sea el del tráfico ilícito de estupefacientes, en relación con el cual también existe un riesgo cierto de relajación punitivista de las condiciones de persecución de la correspondiente forma específica de asociación ilícita.

\section{LA ORGANIZACIÓN: SUJETO DE IMPUTACIÓN}

\subsection{LA DISYUNTIVA OBJETO/SUJETO}

Una ventaja de la prescindencia de la etiqueta de la "criminalidad organizada", a favor de su sustitución por la de "organización delictiva", se encuentra en que así pueden eludirse determinados prejuicios que impiden reconocer el protagonismo del factor organizacional en ámbitos delictivos sometidos a otras etiquetas que también reclaman preferencia fenoménica. El caso emblemático parece ser el de la "criminalidad económica"67. El dato fundamental consiste aquí en la imposibilidad de la consideración simultánea de una misma organización como objeto y sujeto de responsabilidad jurídico-

\footnotetext{
${ }^{64}$ En los términos de VON WRIGHT (1970) pp. 90 s., se trata entonces de circunstancias contextuales de las cuales depende -al menos en el caso ordinario de la integración o el favorecimiento de la asociación- la aplicabilidad de la prohibición, y no de circunstancias que integren ("directamente") la descripción de la forma de comportamiento prohibida.

${ }^{65}$ En este sentido Toepel (2003) pp. 68 ss. Tal es la función, verbigracia, del art. 19 a) de la Ley 20.000, que se refiere a la integración de una "agrupación o reunión de delincuentes" que no alcanza a constituir "delito de organización".

${ }^{66}$ Véase al respecto MAÑalich (2009b) pp. 144 ss.

${ }^{67}$ Ilustrativo SOTOMAYOR (2010) pp. 231 ss.
} 
penal ${ }^{68}$. Pues no es posible que una misma organización cuente, desde el punto de vista del derecho, como persona jurídica y a la vez como asociación ilícita.

Esto ha sido advertido por el legislador chileno con ocasión de la entrada en vigencia de la Ley 20.393, que establece un régimen de responsabilidad penal de personas jurídicas. Pues mediante la misma ley se añadió un inciso $2^{\circ}$ al art. 294 bis del Código Penal, que dispone que, tratándose de una asociación ilícita que "se hubiere formado a través de una persona jurídica", ha de imponerse, como "consecuencia accesoria" a la pena respectiva, "la disolución o cancelación de la personalidad jurídica". Lo notable es que, a pesar de que la disolución o cancelación de la personalidad jurídica cuente como la pena máxima ("capital") establecida dentro del catálogo de penas de la Ley 20.393, en relación con la asociación ilícita se hable de una "consecuencia accesoria", y no de una "pena". Esto sugiere la posibilidad de entender esta consecuencia accesoria al modo de una "sanción declarativa": la organización constitutiva de una asociación ilícita no es, porque no puede ser -esto es lo que se declara-, una persona jurídica, es decir, una organización jurídicamente reconocida como persona ${ }^{69}$. Pues como observa Lampe: "[c]ontra una agrupación que para el derecho nunca ha existido, el Derecho no puede tomar medida alguna"70.

Lo que aquí interesa, sin embargo, es la cuestión inversa: si una determinada organización en efecto recibe reconocimiento jurídico, ¿entonces cabría o no, y en su caso, cómo, construir su estatus como posible portadora -esto es, como sujeto- de responsabilidad jurídico-penal? El legislador chileno, a través de la Ley 20.393, ha respondido categóricamente la primera de las dos preguntas, en sentido afirmativo, aunque restringiendo considerablemente el catálogo delictivo correspondiente ${ }^{71}$. Baste con apuntar, de paso, que uno de los tres componentes específicos de este catálogo está constituido por la forma delictiva más representativa del posible entrecruzamiento de la "criminalidad económica" y la "criminalidad organizada": el lavado de activos ${ }^{72}$. Igualmente relevante, empero, es la circunstancia de que la segunda pregunta todavía necesite una respuesta. Mas esta pregunta por definición no la responde el legislador, sino quienes han de dar cuenta, racionalmente, de su producto legislativo.

${ }^{68}$ Nótese que esa imposibilidad no se da tratándose de la consideración de una organización como objeto o sujeto, por una parte, y como contexto de atribución de responsabilidad, por otra. Pues tanto entre los miembros de una organización calificada como asociación ilícita como entre los miembros de una organización reconocida como persona jurídica pueden plantearse preguntas de distribución y atribución de responsabilidad jurídico-penal por uno o más hechos delictivos determinados: bajo cualquiera de las dos calificaciones, la organización puede servir de contexto de imputación.

69 Esto lo desconoce SEGOVIa (2010) pp. 230, 232 s., quien sostiene que aquí se trataría de un "segundo modelo de atribución de responsabilidad" a las personas jurídicas.

${ }^{70}$ LAMPE (2003) p. 152.

71 Puesto que aquí interesa el contexto de justificación, y no el de descubrimiento, no es necesario atender a "la historia fidedigna" del establecimiento de la ley, que eventualmente explique, en términos de sociología de la legislación, esa restricción. Al respecto véase HERNÁNDEZ (2010) pp. 208 ss.

72 Véase al respecto FERNÁNDEZ (2009) passim. 


\subsection{EL DILEMA}

Parecería trivialmente cierto, ahora bien, que solo tiene sentido responder la segunda pregunta -la del cómo- si la primera -la del sí o no- ya ha sido afirmativamente respondida. Esto no quiere decir, sin embargo, que en pos de responder la pregunta del cómo uno no pueda aprender de quienes han respondido negativamente la pregunta del sí o no, aferrándose al dogma -en el buen sentido: aquello que es cultivado por la "dogmática" - societas delinquere non potest. Recientemente, una defensa de la imposibilidad de afirmar una genuina responsabilidad jurídico-penal de personas jurídicas ha sido ofrecida por Van Weezel ${ }^{73}$. Aquí es suficiente detenerse en la siguiente toma de posición, que sintetiza su argumento:

El dilema de la responsabilidad penal de las personas jurídicas radica en que no existe una opción intermedia o de compromiso que permita tomar realmente en serio a la persona jurídica como sujeto penal, pues ello significa liberar de responsabilidad a la persona natural que encarna el órgano, o bien estar dispuesto a echar por la borda el principio de culpabilidad ${ }^{74}$.

Los dos polos del dilema se corresponden con los dos modelos "puros" de fundamentación de la responsabilidad de las personas jurídicas, perennemente invocados en la discusión: el modelo de transferencia de responsabilidad (o "heterorresponsabilidad") y el modelo de responsabilidad por el hecho propio (o "autorresponsabilidad") ${ }^{75}$. En la medida en que el dilema sea insoluble, y en tanto sea cierto que el régimen de responsabilidad establecido en la Ley 20.393 no represente más que una solución de compromiso, cuya naturaleza precisa dependerá de qué función específica se asigne al factor "defecto de organización” exigido por el art. $3^{\mathrm{o} 76}$, entonces la conclusión alcanzada por Van Weezel parece incontestable.

La formulación más aguda del dilema denunciado por Van Weezel es imputable a Jakobs $^{77}$. El argumento decisivo en contra de la viabilidad del modelo de responsabilidad por transferencia se encuentra, según Jakobs, en que el titular del ámbito de responsabilidad desde el cual tendría que producirse esa "transferencia" no deja de ser portador de responsabilidad por el hecho: el órgano sigue siendo persona (natural), y en tanto tal, sigue siendo plenamente responsable de la infracción de sus propios deberes, lo cual muestra que él no es, en rigor, un mero "órgano"78. La fuerza del argumento de Jakobs

\footnotetext{
73 VAN WEEZEL (2010) pp. 123 ss.

74 VAN WEEZEL (2010) p. 131.

75 Por todos Silva (2002) pp. 160 ss.

76 Véase por ejemplo HeRnÁNDEZ (2010) pp. 216 ss., quien entiende que la ley habría introducido un "modelo atenuado de responsabilidad derivada"; en la dirección inversa SEGOVIA (2010) pp. 230 ss., según quien la ley haría suyo un modelo de autorresponsabilidad, bajo el cual el hecho imputable a la persona jurídica consistiría en la omisión de implementación de un modelo de prevención de delitos, mientras que el hecho delictivo específicamente imputable a la respectiva persona natural contaría como una condición objetiva de la punibilidad del hecho de la persona jurídica.

77 JAKOBS (2002) pp. 67 ss.

78 JAKOBS (2002) pp. 76 ss.
} 
estriba en su clarísima sugerencia de que el problema no radica en la imposibilidad de concebir un actuar superviniente de la persona jurídica a través del actuar de su órgano que sería, "además”, una persona natural, sino más bien en la significación del carácter específicamente delictivo del actuar de este último. Pues es en exclusiva atención a este carácter delictivo del actuar del órgano, consistente en la infracción de un deber impuesto por una norma jurídico-penalmente reforzada, que su actuar, irónicamente, no puede ser interpretado como el simple actuar de un "órgano".

Aquí puede ser útil detenerse en la manera en que Philip Pettit levanta su argumento a favor de la tesis de que es posible reconocer personalidad a sujetos colectivos. Para esto, Pettit se vale en primer lugar de la distinción entre colectividades agregadas y colectividades integradas, para así sostener que solo una colectividad integrada puede llegar a constituir un agente colectivo irreducible a la sola agregación de los agentes individuales que lo componen ${ }^{79}$. Y lo distintivo de un sujeto colectivo es que en ellos los miembros individuales se verían integrados a patrones de juicio y decisión que responden a requerimientos racionales en ese mismo nivel de integración, a consecuencia de lo cual -y esto es lo decisivo- los juicios y en general la intencionalidad del colectivo pueden perfectamente mostrar discontinuidad respecto de los juicios y la intencionalidad de los individuos que lo integran ${ }^{80}$. Esto lleva a que Pettit sostenga que la personalidad "artificial" - aunque perfectamente "real"- de tales colectividades integradas descansa en la posibilidad de considerarlas como "agentes a los cuales dan vida individuos por la vía de suspender sus propios proyectos, de cuando en cuando, en orden a ponerse al servicio del punto de vista colectivo" ${ }^{81}$. Y es esto, entonces, lo que según Jakobs no admite el derecho penal: cuando se trata del proyecto de seguir lealmente una norma de comportamiento jurídico-penalmente reforzada, el derecho no acepta semejante suspensión de la agencia individual en pos de la agencia colectiva. Pues se trata aquí del seguimiento de normas que imponen deberes personalísimos. El problema no es ontológico, sino normativo.

Por su parte, el argumento decisivo en contra de la viabilidad del modelo de responsabilidad por el hecho propio consiste, siguiendo a Jakobs, en que la persona jurídica exhibiría una "personalidad puramente pasiva", incompatible con los presupuestos de una atribución de culpabilidad por el hecho ${ }^{82}$ : la identidad personal necesaria para la culpabilidad por el hecho exigiría una reflexividad de la consciencia en cuanto a la toma de posición en contra (de una norma) del derecho -es decir, una capacidad de

\footnotetext{
79 Véase PETTit (2001) pp. 110 ss.

80 PETTIT (2001) pp. 114 s.

81 PETTIT (2001) p. 119.

82 JAKOBS (2002) pp. 79, 87 ss. Constituye un lugar común apuntar aquí que, de este modo, Jakobs abandona su sugerencia previa, favorable al reconocimiento de la capacidad de culpabilidad jurídico-penal de las personas jurídicas (JAKOBS [1991] 6/45), en razón de que esa toma de posición habría desconocido "la relatividad de la personalidad" (JAKOBS [2002] p. 67, nota 7). Un esbozo de desarrollo de la concepción del "primer Jakobs" para fundamentar la culpabilidad de la persona jurídica se encuentra en BACIGALUPO (2002) pp. 122 ss. Para una valoración crítica de ese intento, basado en el convencimiento de la posibilidad de fundamentar -contra el "segundo Jakobs"- la culpabilidad de la persona jurídica en la concepción del "segundo Jakobs", véase GÓMEZ-JARA (2005) pp. 211 ss.
} 
intencionalidad de segundo orden ${ }^{83}$-, mientras que la identidad de una persona jurídica sería función exclusiva de su configuración estatutaria. Es efectivo, ahora bien, que se han elaborado propuestas, prolijas y ambiciosas como la de Gómez-Jara, de redefinir funcionalmente el concepto de culpabilidad de modo tal de hacerlo aplicable, sin maniobras ad hoc, a empresas cuya complejidad interna sea suficiente para un reconocimiento de autorreferencialidad en su operación, sobre la cual emerja una capacidad de autoorganización reflexiva ${ }^{84}$. Pero semejante concepción se ve enfrentada a dos objeciones que pueden resultar capitales, y que cabría denominar "la objeción de la teoría del delito" y "la objeción de la teoría de la pena".

La objeción de la teoría del delito apunta a la falta de plausibilidad de una concepción favorable a una genuina culpabilidad por el hecho de la persona jurídica. Pues todo el esfuerzo conceptual por construir una culpabilidad por el hecho que sea predicable de la persona jurídica se traduce en una absoluta disolución del hecho al cual tendría que referirse esa culpabilidad ${ }^{85}$. Para esto, es suficiente considerar la definición de "hecho" que Gómez-Jara se ve forzado a esbozar: "se abre un entendimiento normativo del "hecho" como configuración de un ámbito de organización" 86 . Mas si es la capacidad de autoorganización reflexiva de la organización empresarial lo que fundamenta su capacidad de culpabilidad, entonces es difícil ver cómo la definición del "hecho" al cual tendría que referirse esa culpabilidad no termine siendo estrictamente circular, y en tal medida vacía. Pues la definición de Gómez-Jara se traduce en la proposición cuasitautológica de que la persona jurídica sería culpable de un ejercicio de su propia capacidad de ser culpable. Tal concepto de hecho, por lo demás, es enteramente inservible para la eventual subsunción de su referente bajo tipificaciones delictivas específicas, como las del lavado de dinero, el cohecho activo o el financiamiento de actividades terroristas, que es precisamente, sin embargo, lo que exige una regulación legal como la chilena ${ }^{87}$.

La objeción de la teoría de la pena no es más fácil de salvar. En su intento por elaborar un concepto de culpabilidad por el hecho aplicable a organizaciones empresariales, Gómez-Jara advierte la necesidad de una fundamentación material del correspondiente reproche de culpabilidad referido a un quebrantamiento imputable del derecho. Y él advierte, además, que esa fundamentación tendría que ser dependiente de la adscripción a la organización empresarial de un estatus análogo al del ciudadano ${ }^{88}$, en el sentido de lo que tradicionalmente se denomina un modelo de "ciudadano corporativo (o societario)". Más allá de si es plausible o no la interpretación de la libertad (constitu-

\footnotetext{
83 Véase MAÑALiCH (2009a) pp. 279 ss.; MAÑALiCH (2009c) pp. 191 ss.

${ }^{84}$ GÓMEZ-Jara (2005) pp. 201 ss., 241 ss.

85 Véase SilVA (2002) pp. 167 s.

86 GÓMEZ-JARA (2005) pp. 279 s.

${ }^{87}$ Resaltan la importancia de esto HernándeZ (2010) p. 218, con nota 47; VAN WEEZEL (2010) p. 122. El intento de sostener que el hecho propio de la persona jurídica consistiría en la omisión de la implementación de un modelo de prevención de delitos -así SEGOVIA (2010) pp. 230 s.- resulta difícilmente verosímil ante la afirmación de que la implementación de tal modelo no sería obligatoria, sino solo "facultativa" -así SEGOVIA (2010) p. 232- para la persona jurídica.

${ }^{88}$ GÓMEZ-JARA (2005) pp. 286 ss., 289 ss.
} 
cional) de expresión susceptible de ser reconocida a las personas jurídicas en el sentido de una libertad positiva -esto es, como una posición de autonomía pública-, en lo cual Gómez-Jara pone buena parte del énfasis, es más que discutible la conclusión de que la organización empresarial moderna exhibiría "una capacidad para expresar juicios morales en el discurso del foro público", que la habilitaría a tomar parte en la "producción común de sentido" 89 .

Esta última afirmación tiene algunas implicaciones ético-políticas sumamente problemáticas, que apenas logran ser advertidas si la discusión se reduce a la cuestión "formal" del sufragio. Pues la discusión no se zanja con la constatación de que las organizaciones empresariales por definición carecen del derecho a voto propio de la ciudadanía democrática, ante lo cual habría que buscar algo así como el correspondiente "equivalente funcional”. El problema pasa, más bien, por la razón que justifica que no se reconozca derecho a voto a una organización empresarial. Y esta razón concierne un dato fundamental de cualquier régimen democrático: detrás del principio "un hombre (o una mujer), un voto" se esconde un principio elemental de no dominación recíproca entre quienes -supuestamente- practican el autogobierno ${ }^{90}$. El procedimiento democrático pretende institucionalizar el desiderátum de que la capacidad de incidencia política de cada cual no sea mayor ni menor que la de cualquiera de los demás, de modo tal que cada ciudadano pueda reclamar (igual) autoría respecto de lo que el art. 10 del Código Civil denomina la "declaración de la voluntad soberana"91. Y si bien sería particularmente ingenuo pensar que el procedimiento democrático en efecto logre realizar ese desiderátum, no es difícil advertir que un reconocimiento de "agencia política" a las organizaciones empresariales tendría que contar como una desfachatada confesión de la renuncia a la realización de ese postulado de igual ciudadanía. Pues un reconocimiento de agencia política a la empresa no resulta diferenciable de un correspondiente reconocimiento de agencia política al empresario o "emprendedor".

Lo anterior es ciertamente dependiente de la manera en que una organización empresarial podría incidir, de hecho, en los procesos de deliberación política. Tomando en serio el argumento de Gómez-Jara, habría que concluir que el modo por el cual las organizaciones empresariales participan en la "producción común de sentido" no se alejará demasiado de la práctica que denominamos lobby, la cual no es en absoluto inocente en atención a la posibilidad de una sustancial erosión de la praxis democráti$\mathrm{ca}^{92}$. Y en este sentido, resulta al menos irónico que sea la práctica del lobby lo que puede transformarse, más temprano que tarde, en la perpetración de un hecho constitutivo de soborno o cohecho activo, que es precisamente uno de los tipos delictivos a cuya realización la Ley 20.393 asocia la eventual atribución de responsabilidad a una persona jurídica.

\footnotetext{
${ }^{89}$ GÓMEZ-JARA (2005) pp. 290 ss.

${ }^{90}$ Fundamental PeTtiT (2001) pp. 125 ss., 138 ss.

${ }^{91}$ Sobre esta dimensión "autoral" de la ciudadanía democrática, véase PetTit (2001) pp. 160 ss.

92 Véase Petтit (2001) p. 162.
} 


\subsection{Culpabilidad POR El CARÁCTER}

El balance que arroja la brevísima revisión precedente es contrario a la plausibilidad de la reconstrucción de un modelo de responsabilidad jurídico-penal de las personas jurídicas que sea compatible con las implicaciones elementales del principio de culpabilidad por el hecho. Pero esto no significa que entonces haya que renunciar, necesariamente, a fundamentar la responsabilidad jurídico-penal de las personas jurídicas, legalmente prevista, en la noción de culpabilidad. La tesis, más bien, es la siguiente: la culpabilidad de la persona jurídica debe ser entendida como una culpabilidad por el carácter.

La razón decisiva para sostener esta tesis se encuentra en su altísimo rendimiento explicativo. Pero antes de demostrarlo es imprescindible descartar, de entrada, la tradicional objeción dirigida contra el concepto de culpabilidad por el carácter. Y para esto existe una explicación, literalmente, gramatical. La preposición "por", que figura en la expresión "responsabilidad por el carácter", exhibe aquí un notable grado de ambigüedad. Cuando se discute acerca de la noción de una responsabilidad por el carácter, generalmente no queda demasiado claro si lo que interesa es el carácter como objeto o como posible base de responsabilidad personal; esto es, si la referencia al carácter concierne la pregunta de qué es aquello de lo cual se es (o se puede ser) responsable, o bien la pregunta de por qué se es responsable de algo ${ }^{93}$.

La posibilidad de elaborar un modelo de responsabilidad por el carácter, en la tradición del moderno derecho penal, ha estado fundamentalmente asociada a la atribución de responsabilidad a una persona individual, porque este es el paradigma de persona jurídico-penalmente responsable. En este contexto, la tesis de una responsabilidad por el carácter ha operado al modo de una posible postulación del carácter como base o criterio último de responsabilidad penal ${ }^{94}$. Hablar aquí de un criterio último supone que, de ser plausible la tesis, el carácter de una persona podría ser esgrimido como la razón que, en último término, fundamenta su responsabilidad por el hecho en cuestión. Esto, en la medida en que por "carácter" puede entenderse aquí, gruesamente, la aptitud de una persona para exhibir un determinado sello, que le provee disposiciones, tendencias y propiedades más o menos estables en el tiempo ${ }^{95}$. Y la persona, siendo moralmente adulta, no puede esgrimir su carácter para exonerarse de tal responsabilidad, precisamente porque no sería admisible su pretensión de tomar distancia de su propio carácter,

\footnotetext{
93 DAN-COHEN (1992) pp. 962 ss.

94 Fundamental ENGISCH (2006) pp. 124 ss., 144 ss. Esto no supone en modo alguno desconocer que Engisch articuló su concepción de la culpabilidad por el carácter en referencia exclusiva a la fundamentación de responsabilidad de la persona natural, habiendo rechazado toda posibilidad de fundamentar una culpabilidad de la persona jurídica. Al respecto véase GÓMEZ-JARA (2005) pp. 183 s., nota 21. Aquí únicamente se trata, por lo mismo, de una sustracción de esa concepción -desafiando la voluntad de su autor- para hacerla aplicable a la fundamentación de la culpabilidad de la persona jurídica.

95 ENGISCH (2006) p. 145. En la literatura psicoanalítica es posible encontrar la siguiente definición, ya clásica, ofrecida por REICH (2005) p. 167: “El carácter consiste en una alteración crónica del yo, a la que podríamos calificar de rigidez. Es la base de la cronicidad del modo de reacción característico de una persona. Su significado es la protección del yo contra peligros exteriores e interiores. Como mecanismo de protección que se ha hecho crónico, puede denominársele con todo derecho una coraza".
} 
que en tal medida es constitutivo de sí misma ${ }^{96}$. La persona puede ser responsable, ciertamente, de un hecho determinado, esto es, de haber hecho (o dejado de hacer) algo; pero podrá ser responsable en virtud de que en ese hecho se expresa su propio carácter, esto es, su propia identidad ${ }^{97}$.

Esto quiere decir, sin embargo, que respecto de personas naturales el carácter podría ser entendido como un criterio (último), pero no como objeto de responsabilidad jurídico-penal. Pues el objeto del reproche jurídico-penal dirigido a una persona natural solo puede estar constituido, en tal medida, por el quebrantamiento de una norma públicamente vinculante. Y paradigmáticamente al menos, el destinatario del reproche de culpabilidad cuenta tanto como persona a la cual se reconoce dignidad intrínseca, cuanto como ciudadano al cual se reconoce autonomía política ${ }^{98}$.

Pero tratándose de una persona jurídica, parece posible entender su carácter ya no como base, sino como objeto de responsabilidad personal ${ }^{99}$. Esto, por una parte, porque tratándose de una persona jurídica cabe poner en duda la posibilidad de identificar un hecho suyo que no resulte, en los términos ya analizados, plenamente imputable a una o más personas naturales a través de cuya agencia (primaria) la persona jurídica adquiere su propia agencia (secundaria). Dicho de otra manera: no resulta convincente la imagen de la persona jurídica como autora mediata de lo que hacen sus "agentes". Y por otra parte, porque siendo la identidad de una persona jurídica "en un cien por ciento funcional" ${ }^{100}$, ella carece de dignidad intrínseca, de manera tal que no hay obstáculo alguno a que pueda dirigírsele un reproche directamente referido a su modo de ser, esto es, a su carácter ${ }^{101}$. Pues frente a una persona jurídica en general no adoptamos lo que cabría denominar una actitud personal ${ }^{102}$, que es la marca del reconocimiento de personalidad en sentido moral, y que coincide, en el caso paradigmático, con el uso adscriptivo del concepto de persona tratándose de personas naturales ${ }^{103}$.

96 Acerca de la noción de autoconstitución como implicación de la noción de autodeterminación, véase MAÑALich (2009a) pp. 292 ss.; MAÑALich (2009c) pp. 196 ss.

97 Y ello cuenta, siguiendo a Kant, como la enunciación de la condición de posibilidad de toda atribución de responsabilidad personal por un hecho (moral, ética o jurídicamente) incorrecto, a saber, la presuposición de que una persona es responsable de lo que hace (o deja de hacer) porque en el hecho que se le imputa se expresa quién y cómo esa persona es, en circunstancias que esa misma persona es responsable de ser quien y como es. Esto hace posible, según sugiere Kant, ofrecer una reinterpretación de la imagen del "pecado original" desprovista de sus eventuales connotaciones mitológicas, como la expresión de un postulado de la razón práctica cuya fundamentación es enteramente pragmática. Véase KANT (1977) pp. 678 ss.

${ }^{98}$ Latamente al respecto MAÑALICH (2007) pp. 142 s., 152 ss., 168 ss., 183 ss.

99 Fundamental acerca de la estructura de la responsabilidad “por” el carácter, DAN-COHEN (1992) pp. 973 ss.

100 VAN WEEZEL (2010) p. 127.

101 LAMPE (2003) pp. 161 ss.

102 Fundamental al respecto STRAWSON (1995) pp. 41 ss., 61 ss.

103 Un concepto adscriptivo de persona designa a cualquiera entidad que cuenta como destinataria idónea de una atribución o adscripción de responsabilidad personal. Un concepto prescriptivo de persona, en cambio, designa a cualquier entidad que cuenta como titular idóneo de derechos (subjetivos) que tienen como correlato deberes cuya infracción constituye una "lesión de la personalidad". Por eso, un niño de cinco años puede ser persona en sentido prescriptivo, aunque no en sentido adscriptivo. Fundamental acerca del uso adscriptivo del concepto de persona, DennetT (1981) pp. 239 s., 267 ss. Para un análisis 
Así, a diferencia de lo que es el caso tratándose del reproche dirigido a una persona natural, el derecho no se contradice a sí mismo si dirige un reproche a una persona jurídica cuya estructura declarativa sea: "esta persona no debe ser". Y aquí hay que notar que el "modo de ser" de una persona jurídica resulta fácilmente determinable, a consecuencia de su ontología específica. Las personas jurídicas son, esencialmente, personas institucionales, esto es, personas cuya existencia está enteramente construida -sin que esto la haga menos "real" 104 - sobre un complejo artefacto de prácticas, reglas y convenciones que generan, distintivamente, determinadas posibilidades y contextos de acción previamente inexistentes ${ }^{105}$.

Lo anterior no quiere decir, sin embargo, que el hecho delictivo específicamente atribuible a la respectiva persona natural carezca de relevancia para la formulación de ese reproche de culpabilidad por el carácter dirigido a la persona jurídica. Pues en la medida que las propiedades asociadas a un carácter defectuoso son latentes o disposicionales (y no manifiestas), es imprescindible que ese carácter defectuoso se exprese sintomáticamente. Esto hace posible explicar, por de pronto, la exigencia legal de la realización de un hecho delictivo -constitutivo de lavado de dinero, cohecho activo o financiamiento de terrorismo- imputable a un órgano de la persona jurídica, que cuente como la consecuencia de un defecto organizacional de esta; es decir, del incumplimiento de los respectivos "deberes de dirección y supervisión” (art. 3º inc. 1º Ley 20.393). Así, la función del hecho delictivo no es la de fungir como el objeto de la respectiva responsabilidad, sino como el criterio de reconocimiento o "síntoma" del carácter defectuoso de la persona jurídica, que es aquello de lo cual se la hace responsable ${ }^{106}$. Con ello desaparece cualquier riesgo de una eventual contravención del principio ne bis in idem que pudiera estar asociada a la (supuesta) "doble" sanción penal de la persona natural y la persona jurídica ${ }^{107}$. Y así también puede

del uso prescriptivo del concepto de persona véase, por ejemplo, BIRNBACHER (2006) pp. 53 ss. En todo caso, ni para el uso adscriptivo ni para el uso prescriptivo del concepto de persona cuenta como condición necesaria, desde el punto de vista moral, que lo designado por ese concepto sea un individuo de la especie humana. El estatus de miembro (individual) de la especie humana puede contar, sin embargo, como condición necesaria asociada al concepto de persona en sentido jurídico, tal como es el caso, por ejemplo, de conformidad con la definición de "persona" (natural) ofrecida por el art. 55 del Código Civil, complementado por el art. 74 en cuanto a la identificación del nacimiento como el momento que cuenta como el principio de su existencia. La crítica a la tesis de que el término "persona” designaría una clase natural, cuya extensión quedaría en todo caso restringida a individuos vivos de la especie homo sapiens, se encuentra, por ejemplo, en FRENCH (1983) pp. 243 ss., quien tiende a no reconocer espacio, sin embargo, para una distinción entre personalidad en sentido moral y personalidad (solo) en sentido jurídico (pp. 251 ss.).

104 Frente a la disputa tradicional entre las teorías de la ficción y las teorías de la realidad, en cuanto a la "existencia” de las personas jurídicas, conserva su vigor el célebre dictum kelseniano: "la denominada persona física es una persona jurídica” (KELSEN [1991] p. 184).

105 Fundamental para la ontología de los hechos institucionales, SEARLE (1995) pp. 31 ss.

106 Véase ENGISCH (2006) pp. 136 s.

107 Esto, ciertamente, desde el punto de vista de los respectivos fundamentos de la responsabilidad de la persona natural que comete el hecho delictivo y de la persona jurídica cuyo carácter defectuoso se expresa en el hecho delictivo. Cuestión distinta es si la forma específica de sanción penal asociada a cada uno de esos regímenes de responsabilidad en efecto no se traduce en una "transferencia" de la sanción. Una acertada discusión del problema, en referencia a la imposición de penas pecuniarias, se encuentra en NORRIE (2006) pp. $101 \mathrm{~s}$. 
dotarse de contenido plausible al principio de responsabilidad autónoma de la persona jurídica, proclamado por el art. $5^{\circ}$ de la ley ${ }^{108}$, en la medida en que el objeto de la responsabilidad atribuida a la persona jurídica de hecho no coincide con el objeto de responsabilidad eventualmente atribuida a la respectiva persona natural.

Además, la tesis de la culpabilidad por el carácter permite dar cuenta, sin mayor dificultad, de un dato ulterior de la regulación legal, representado por los dos requisitos copulativos exigidos por el art. $3^{\circ}$ : por una parte, que el hecho delictivo específico represente la consecuencia del incumplimiento de los respectivos deberes de dirección y supervisión; por otra, que el hecho haya sido cometido "en interés o para el provecho" de la persona jurídica. Entendidos como criterios copulativos de manifestación del carácter defectuoso de la persona jurídica en el hecho delictivo de la persona natural, cada uno de ellos puede ser reformulado, negativamente, como un correspondiente criterio de descargo: si el hecho se produce a pesar de haberse adoptado e implementado un modelo de prevención (art. $3^{\circ}$ inc. $3^{\circ}$, en relación con el art. $4^{\circ}$ ), entonces el hecho no es manifestación de un carácter defectuoso de la persona jurídica; y si el hecho es cometido por el órgano exclusivamente "en ventaja propia o de un tercero" (art. $3^{\circ}$ inc. final), entonces no es el (eventual) carácter defectuoso de la persona jurídica lo que se manifiesta en el hecho.

El rendimiento explicativo de la tesis de la culpabilidad por el carácter no se restringe, empero, al conjunto de los presupuestos de la responsabilidad, sino que alcanza también algunas notas básicas del régimen de penalidad. De un lado, ella posibilita mantener la legitimidad prima facie de una forma de sanción penal que sería sin más inaceptable bajo un régimen de culpabilidad por el hecho: la exterminación de la personalidad del condenado, que aquí asume la forma de la disolución o bien de la cancelación de la personalidad jurídica (art. $8^{\circ} \mathrm{N}^{\circ} 1^{\circ}$ y art. 9o Ley 20.393). Un reproche de culpabilidad por el carácter, a diferencia de un reproche de culpabilidad por el hecho ${ }^{109}$, no constituye una autocontradicción realizativa si se materializa en la destrucción de la persona cuyo "modo de ser" se censura. Y de otro lado, la tesis de la culpabilidad por el carácter hace posible explicar como autoevidente el hecho de que la única circunstancia agravante prevista por la Ley 20.393 sea la reincidencia específica (art. 70), lo cual es manifiestamente incompatible con un régimen de determinación de la pena orientado a la culpabilidad por el hecho, resultando congruente, en cambio, con la adopción de un principio de culpabilidad por el carácter o por la "conducción de (la propia) vida". Nótese, por lo demás, que de la configuración de esa agravante depende la posibilidad de imposición de la pena - “máxima”- de disolución o cancelación de la personalidad jurídica (art. $9^{\circ}$ inc. final).

\subsection{DE LEGE FERENDA}

La pregunta que queda pendiente concierne la funcionalidad latente del establecimiento de un régimen de responsabilidad jurídico-penal de organizaciones reconocidas

108 Críticamente HERNÁNDEZ (2010) pp. 221 ss. 
como personas jurídicas. Es indudable que el catálogo de las formas delictivas a cuya realización se encuentra vinculada la eventual afirmación de responsabilidad de una persona jurídica es demasiado restringido, resultando excluidos "los delitos de mayor trascendencia relacionados con la actividad empresarial" ${ }^{110}$. Lo cual se ve agravado por los defectos que muestra la tipificación legal de una de las tres formas delictivas sí incluidas, el lavado de activos ${ }^{11}$. Ello parecería aconsejar una ampliación decidida del catálogo en cuestión. Pero aquí emerge, finalmente, una nota de cautela, en relación con la posible ideología profunda de la regla del art. 5º inc. final, de la Ley 20.393. Esta disposición hace posible afirmar la responsabilidad de la persona jurídica cuando "habiéndose acreditado la existencia de alguno de los delitos establecidos en el art. $1^{\mathrm{o}} \mathrm{y}$ concurriendo los demás requisitos previstos en el art. $3^{\circ}$, no haya sido posible establecer la participación de el o los responsables individuales"112. ¿Es posible descartar que esta regla en definitiva opere como un mecanismo favorecedor de la elusión de la responsabilidad de las personas naturales que se desempeñan como directivos de la persona jurídica, por la vía de que el órgano persecutor se contente con demostrar "fehacientemente que el delito debió necesariamente ser cometido dentro del ámbito de funciones y atribuciones propias de las personas señaladas en el inciso primero del mencionado art. $3^{\circ}$ ”?

La cautela es necesaria, porque si no podemos descartar tal posibilidad, quizá haya razones para temer que, a través de esa regla, el legislador chileno efectivamente haya introducido un modelo de genuina responsabilidad por transferencia.

\section{BIBLIOGRAFÍA CITADA}

BACIGALUPO, Silvina (2002): "La responsabilidad penal de las personas jurídicas: un problema del sujeto del derecho penal”, en: GARCía CAVERO, Percy (coord.), La responsabilidad penal de las personas juridicas. Órganos y representantes (Lima, Ara) pp. 99-140.

Binding, Karl (1905): Lehrbuch des Gemeinen Deutschen Strafrechts. Besonderer Teil (Leipzig, Wilhelm Engelmann) 1.005 pp.

BIRNBACHER, Dieter (2006): Bioethik zwischen Natur und Interesse (Frankfurt, Suhrkamp) 395 pp.

CANCIO, Manuel (2008): "El injusto de los delitos de organización: peligro y significado", en: CAnCIO, Manuel y Silva, Jesús, Delitos de organización (Montevideo y Buenos Aires, BdF) pp. 15-84.

CANCIO, Manuel (2010): "El delito de pertenencia a una organización terrorista en el Código Penal español”, Revista de Estudios de la Justicia 12, pp. 147-164.

CARnevalli, Raúl y Fuentes, Hernán (2008): "Informe jurídico sobre la eventual aplicación del delito de asociación ilícita establecido en el art. 16 de la Ley $\mathrm{N}^{\circ}$

\footnotetext{
${ }^{109}$ En relación con la pena de muerte, MAÑALICH (2007) pp. 174 ss.

110 HeRnándeZ (2010) pp. 215 s.

111 Véase la valoración crítica de FERNÁNDEZ (2009) pp. $12 \mathrm{~s}$.

112 Véase HERNÁNDEZ (2010) pp. 223 s.
} 
20.000". Politica criminal 6, disponible en http://www.politicacriminal.cl/n_06/ d_1_6.pdf

Cury, Enrique (2005): Derecho Penal Parte General, 8a ed. (Santiago, Ediciones Universidad Católica de Chile) 812 pp.

Dan-COHEn, Meir (1992): "Responsibility and The Boundaries of The Self", Harvard Law Review 105, pp. 959-1003.

Dennett, Daniel (1981): Brainstorms. Philosophical Essays on Mind and Psychology (Cambridge, Mass., The MIT Press) 353 pp.

ENGISCH, Karl (2006): La teoría de la libertad de la voluntad en la actual doctrina filosófica del derecho penal (Traducc. José Luis GUZMÁN DALBORA, Valparaíso, Edeval) $173 \mathrm{pp}$.

EtCheberry, Alfredo (1998): Derecho Penal Parte General, 3a ed., tomo I (Santiago, Editorial Jurídica de Chile) 361 pp.

FERnÁNDEZ, José Ángel (2009): "Fraude fiscal y lavado de capitales”, Política Criminal 7, A 5-7, disponible en http://www.politicacriminal.cl/Vol_04/n_07/Vol4N7A5.pdf

FrenCH, Peter (1983): "Kinds and Persons", Philosophy and Phenomenological Research 44, No 2, pp. 241-254.

Gimbernat, Enrique (2007): Autor y cómplice en derecho penal (Buenos Aires, Montevideo, BdF) 334 pp.

GÓmEZ-JARA, Carlos (2005): La culpabilidad penal de la empresa (Madrid y Barcelona, Marcial Pons) 365 pp.

GuZmán DAlbora, José Luis (2007): “Objeto jurídico y accidentes del delito de asociaciones ilícitas", en: GUZMÁN DALBORA, José Luis, Estudios y defensas penales, 2a ed. (Santiago, LexisNexis) pp. 93-166.

HERNÁNDEZ, Héctor (2010): "La introducción de la responsabilidad penal de las personas jurídicas en Chile”, Politica Criminal 9, pp. 207-236, disponible en http:// www.politica-criminal.cl/Vol_05/n_09/Vol5N9A5.pdf

JaKOBS, Günther (1991): Strafrecht Allgemeiner Teil. Die Grundlagen und die Zurechnungslehre, 2a ed. (Berlín y Nueva York, Duncker \& Humblot) 944 pp.

JAKOBS, Günther (1997): "Criminalización en el estadio previo a la lesión de un bien jurídico" (Traducc. Enrique PEÑARANDA), en: JAKOBS, Günther, Estudios de Derecho Penal (Madrid, Civitas) pp. 293-324.

JAKOBS, Günther (2002): “¿Punibilidad de las personas jurídicas?” (Traducc. Carlos SuÁreZ), en: GARCÍA CAVERO, Percy (coord.), La responsabilidad penal de las personas jurídicas. Órganos y representantes (Lima, Ara) pp. 63-97.

KANT, Immanuel: Die Religion innerhalb der Grenzen der bloßen Vernunft, en: WEIDESCHEL, Wilhelm (ed.), Werksausgabe, tomo VIII (Suhrkamp, Frankfurt, 1977) 885 pp.

Kelsen, Hans (1991): Teoría pura del derecho, 12a ed. (Traducc. Roberto Vernengo, México, Porrúa) 364 pp.

KINDHÄUSER, Urs (1989): Gefährdung als Straftat. Rechtstheoretische Untersuchungen zur Dogmatik der abstrakten und konkreten Gefährdungsdelikte (Frankfurt, Vittorio Klostermann) 399 pp. 
KINDHÄUSER, Urs (2003): "Cuestiones fundamentales de la coautoría” (Traducc. Manuel Cancio Meliá), Revista Penal 11, pp. 53-70.

KindhäUsER, Urs (2008): "Estructura y legitimación de los delitos de peligro del Derecho Penal” (Traducc. Nuria PASTOR MúNoz), en: KindhäUser, Urs, Teoría de las normas y sistemática del delito (Lima, Ara) pp. 39-61.

KINDHÄUSER, Urs (2010): Strafgesetzbuch. Lehr und Praxiskommentar, 4a ed. (BadenBaden, Nomos) 1.308 pp.

LAMPE, Ernst-Joachim (2003): La dogmática jurídico-penal entre la ontología social y el funcionalismo (Traducc. Carlos GÓMEZ-JARA et al., Lima, Grijley) 264 pp.

LAMPE, Ernst-Joachim (2007): “Tätersysteme: Spuren und Strukturen”, Zeitschrift für die gesamte Strafrechtswissenschaft 119, pp. 471-518.

MAÑAlich, Juan Pablo (2007): “La pena como retribución”, Estudios Públicos 108, pp. 117-205.

Mañalich, Juan Pablo (2008): "Miedo insuperable y obediencia jerárquica", Revista de Derecho UACH XXI, pp. 61-73.

MAÑALICH, Juan Pablo (2009a): Nötigung und Verantwortung. Rechtstheoretische Untersuchungen zum präskriptiven und askriptiven Nötigungsbegriff im Strafrecht (BadenBaden, Nomos) 415 pp.

MaÑAlich, Juan Pablo (2009b): "Pena y ciudadanía”, en: KindHÄUser, Urs y MAÑALICH, Juan Pablo, Pena y culpabilidad en el Estado democrático de derecho (Lima, Ara) pp. 119-147.

MAÑAliCH, Juan Pablo (2009c): “Determinismo, autonomía y responsabilidad penal”, en: KindhäUser, Urs y Mañalich, Juan Pablo, Pena y culpabilidad en el Estado democrático de derecho (Lima, Ara) pp. 181-207.

MAÑAliCH, Juan Pablo (2010a): "Norma e imputación como categorías del hecho punible”, Revista de Estudios de la Justicia 12, pp. 165-185.

MAÑAlich, Juan Pablo (2010b): "La estructura de la autoría mediata", Revista de Derecho PUCV XXXIV, pp. 385-414.

Norrie, Alan (2006): Crime, Reason and History, 2a ed. (Cambridge, Cambridge University Press) 274 pp.

NovoA, Eduardo (2005): Curso de Derecho Penal Chileno, $3^{\mathrm{a}}$ ed., tomo I (Santiago, Ed. Jurídica de Chile) 585 pp.

PetTit, Philip (2001): A Theory of Freedom. From the Psychology to the Politics of Agency (Cambridge, Polity) 193 pp.

REICH, Wilhelm (2005): Análisis del carácter (Traducc. Luis FABRICANT, Barcelona, Paidós) 520 pp.

Roxin, Claus (2000): Autoría y dominio del hecho en derecho penal, $7^{\mathrm{a}}$ ed. (Traducc. Joaquín Cuello y José Luis Serrano, Madrid y Barcelona, Marcial Pons) 797 pp.

Roxin, Claus (2006): "El dominio de la organización como forma independiente de autoría mediata” (Traducc. Justa GÓmEZ NAVAJAS), Revista de Estudios de la Justicia 7, pp. 11-22.

SEARLE, John (1995): The Construction of Social Reality (Nueva York, The Free Press) 241 pp. 
Segovia, Antonio (2010): "Modelos de atribución de responsabilidad penal a las personas jurídicas en la Ley No 20.393", Revista Jurídica del Ministerio Público 43, pp. 218-233.

SiLVA, Jesús (2002): "La responsabilidad penal de las personas jurídicas y las consecuencias accesorias del art. 129 del Código Penal español”, en: García CaVERO, Percy (coord.), La responsabilidad penal de las personas jurídicas. Órganos y representantes (Lima, Ara) pp. 141-212.

SiLVA, Jesús (2008): “La 'intervención a través de organización’, ¿una forma moderna de participación en el delito?”, en: CANCIO, Manuel y SILVA, Jesús, Delitos de organización (Montevideo y Buenos Aires, BdF) pp. 87-118.

SOTOMAYOR, Juan Oberto (2010): "Criminalidad organizada y criminalidad económica: los riesgos de un modelo diferenciado de derecho penal", Revista de Estudios de la Justicia 12, pp. 229-260.

StraWson, Peter (1995): Libertad y resentimiento (Traducc. Juan José ACERO, Barcelona, Paidós) 189 pp.

TOEPEL, Friedrich (2003): "Zur Architektur der Bandendelikte", Zeitschrift für die gesamte Strafrechtswissenschaft 115, pp. 60-90.

VAN WEEZEL, Alex (2009): “Intervención delictiva y garantismo penal”, Zeitschrift für Internationale Strafrechtsdogmatik 8, pp. 432-445, disponible en http://www.zisonline.com/dat/artikel/2009_8_350.pdf

VAN WEEZEL, Alex (2010): “Contra la responsabilidad penal de las personas jurídicas”, Politica Criminal 9, pp. 114-142, disponible en http://www.politicacriminal.cl/ Vol_05/-n_09/Vol5N9A3.pdf

VON WRIGHT, Georg Henrik (1970): Norma y acción. Una investigación lógica (Traducc. Pedro García Ferrero, Madrid, Tecnos) 216 pp.

YÁnEZ, Sergio (1975): "Problemas básicos de la autoría y de la participación en el Código Penal chileno”, Revista de Ciencias Penales XXXIV, No 1, pp. 49-64.

\section{NORMAS CITADAS}

\section{LEGISLACIÓN CHILENA}

Constitución Política de la República de Chile (CPR).

Código Civil.

Código Penal (CP).

Código Procesal Penal (CPP).

Código de Justicia Militar.

Ley 18.314, Determina conductas terroristas y fija su penalidad. Diario Oficial, 17 de mayo de 1984.

Ley 19.913, Crea la unidad de análisis financiero y modifica diversas disposiciones en materia de lavado y blanqueo de activos. Diario Oficial, 18 de diciembre de 2003.

Ley 20.000, Sustituye la Ley No 19.366, que sanciona el tráfico ilícito de estupefacientes y sustancias sicotrópicas. Diario Oficial, 16 de febrero de 2005. 
Ley 20.393, Establece la responsabilidad penal de las personas jurídicas en los delitos de lavado de activos, financiamiento del terrorismo y delitos de cohecho que indica. Diario Oficial, 2 de diciembre de 2009.

LEGISLACIÓN EXTRANJERA

Código Penal español de 1944.

Strafgesetzbuch (Código Penal de la República Federal alemana, StGB). 